\title{
Article
}

\section{Global diversity and phylogeny of Fuscoporia (Hymenochaetales, Basidiomycota)}

\author{
Chen $\mathbf{Q}^{1,2}$, Du $\mathbf{P}^{3}$, Vlasák $\mathrm{J}^{4}$, Wu $\mathrm{F}^{1^{*}}$ and Dai $\mathrm{YC}^{1,2^{*}}$
}

\begin{abstract}
${ }^{1}$ School of Ecology and Nature Conservation, Beijing Forestry University, Beijing 100083, China
${ }^{2}$ Beijing Advanced Innovation Center for Tree Breeding by Molecular Design, Beijing Forestry University, Beijing 100083, China

${ }^{3}$ College of Life Science and Technology, Yangtze Normal University, Chongqing 408100, China

${ }^{4}$ Biology Centre, Czech Academy of Sciences, Institute of Plant Mol. Biol., Branišovská 31, CZ-370 05 České Budějovice, Czech Republic
\end{abstract}

Chen Q, Du P, Vlasák J, Wu F, Dai YC 2020 - Global diversity and phylogeny of Fuscoporia (Hymenochaetales, Basidiomycota). Mycosphere 11(1), 1477-1513, Doi 10.5943/mycosphere/11/1/10

\begin{abstract}
The genus Fuscoporia is characterized by annual to perennial, resupinate to pileate basidiocarps, a dimitic hyphal system with generative hyphae bearing crystals, presence of hymenial setae in most species, and hyaline, thin-walled, smooth basidiospores. To explore the phylogenetic positions of Fuscoporia species, we performed a comprehensive study by using molecular data based on global specimens: a total of 105 specimens including 41 species of Fuscoporia were analyzed, ITS (95 with 46 new), nLSU (94 with 49 new), RPB2 (49 with 34 new) and TEF1 (73 with 52 new) sequences were used to reconstruct Fuscoporia phylogeny. According to our phylogenetic analyses inferred from the nLSU and ITS+nLSU+RPB2+TEF1 datasets, Fuscoporia comprises six distinct groups ( $F$. contigua group, $F$. ferrea group, $F$. ferruginosa group, $F$. gilva group, $F$. torulosa group and $F$. viticola group) and three ungrouped species ( $F$. acutimarginata, $F$. discipes and $F$. insolita). Nine new species, Fuscoporia australasica, $F$. australiana, F. bambusae, F. chinensis, F. eucalypti, F. karsteniana, F. plumeriae, $F$. shoreae and $F$. subchrysea, are described. Two new combinations, Fuscoporia bambusicola and $F$. roseocinerea, are proposed. A key to 49 accepted species of Fuscoporia in worldwide is provided.
\end{abstract}

Key words - Nine new species - Hymenochaetaceae - Phylogeny - Taxonomy - Wood-rotting fungi

\section{Introduction}

Fuscoporia Murrill was introduced by Murrill (1907) with F. ferruginosa (Schrad.) Murrill selected as type species. The genus has been considered as a synonym of Phellinus Quél. sensu lato by many scientists for a long time (Overholts 1953, Lowe 1966, Ryvarden \& Johansen 1980, Cunningham 1948, Larsen \& Cobb-Poulle 1990, Ryvarden \& Gilbertson 1994). Phellinus is the largest genus in the family of Hymenochaetaceae and has a worldwide distribution in the world (Larsen \& Cobb-Poulle 1990). Many important forest pathogens, but also valuable medicinal fungi are currently included in Phellinus sensu lato (Dai et al. 2007, 2010, Wu et al. 2019). Fiasson \& Niemelä (1984) defined Fuscoporia as a monophyletic genus which differs from Phellinus sensu 
stricto by thin-walled basidiospores and encrusted generative hyphae at dissepiments. The genus was re-confirmed as an independent genus (Wagner \& Fischer 2001, 2002), and this conclusion has been widely accepted by Niemelä et al. (2001), Groposo et al. (2007), Baltazar et al. (2009), Dai (2010), Baltazar \& Gibertoni (2010), Raymundo et al. (2013a, b), Spirin et al. (2014), Pires et al. (2015), Chen \& Yuan (2017), Chen et al. (2019) and Chen \& Dai (2019). Fuscoporia is characterized by annual to perennial and resupinate to pileate basidiocarps, a dimitic hyphal system with encrusted generative hyphae at dissepiments and in trama, presence of hymenial setae, presence or absence of mycelial setae, and hyaline, thin-walled, smooth basidiospores (Fiasson \& Niemelä 1984, Dai 2000, 2010). To date, thirty-eigh species are accepted in the genus (Index Fungorum 2020, MycoBank 2020).

Recent studies demonstrated that some traditional species of Fuscoporia are species complexes. For example, Fuscoporia contigua (Pers.) G. Cunn. was defined as a species with variable shape of basidiospores (oblong ellipsoid or cylindric), but some Asian specimens were confirmed as different species based on morphological examinations and phylogenetic analyses. So, F. sinica Y.C. Dai, Q. Chen \& J. Vlasák and F. monticola Y.C. Dai, Q. Chen \& J. Vlasák were segregated from F. contigua (Chen et al. 2019). Similarly, F. ferrea (Pers.) G. Cunn. was considered as a single species occurring in temperate forests of North Hemisphere, but $F$. ramulicola Y.C. Dai \& Q. Chen, F. subferrea Q. Chen \& Y. Yuan and F. yunnanensis Y.C. Dai were derived from $F$. ferrea (Dai 2010, Chen \& Yuan 2017). It is therefore likely that the diversity of Fuscoporia is underestimated.

In this study, we aimed to investigate the diversity and taxonomy of Fuscoporia based on samples from Asia, Europe, Oceania, and America. Nine new species are described and two new combinations are proposed. A phylogeny based on the combined ITS, nLSU, RPB2 and TEF1 DNA sequence data was analysed with a total of 105 specimens including 41 species of Fuscoporia. Six distinctive groups within the Fuscoporia are recovered, viz. F. contigua group, F. ferrea group, $F$. ferruginosa group, $F$. gilva group, $F$. torulosa group, and $F$. viticola group. A key to all 49 accepted species of Fuscoporia is provided.

\section{Materials \& Methods}

\section{Morphological studies}

The studied specimens are deposited in the herbarium of the Institute of Microbiology, Beijing Forestry University (BJFC), Royal Botanic Gardens Victoria (MEL), and the private herbarium of Josef Vlasák (JV) which will be sent to National Museum Prague (PRM). Morphological descriptions are based on field notes and herbarium specimens. Microscopic analyses follow Song \& Cui (2017). In the description: $\mathrm{KOH}=5 \%$ potassium hydroxide, $\mathrm{CB}-=$ acyanophilous in Cotton Blue, IKI- = neither amyloid nor dextrinoid in Melzer's reagent, the microscopical measurements and drawings were made from slide preparations stained with Cotton Blue, $\mathrm{L}=$ arithmetic average of all spore length, $\mathrm{W}=$ arithmetic average of all spore width, $\mathrm{Q}=$ $\mathrm{L} / \mathrm{W}$ ratios, $\mathrm{n}=$ number of spores/measured from given number of specimens. Special color terms are cited from Anonymous (1969) and Petersen (1996).

\section{DNA extraction, PCR and sequencing}

Total genomic DNA was extracted from dried specimens by CTAB rapid plant genome extraction kit (Aidlab Biotechnologies Company, Limited, Beijing, China) according to the manufacturer's instructions with some modifications (Chen et al. 2016). To generate PCR amplicons, the following primer pairs were used: ITS4 and ITS5 (White et al. 1990) for the internal transcribed spacer (ITS), and 983F and 1567R (Rehner \& Buckley 2005) for a region of the translation elongation factor (TEF1), LR0R and LR7 (Vilgalys \& Hester 1990) for the 28S gene region (nLSU) and bRPB2-6F and bRPB2-7.1R (Matheny 2005) for partial RNA polymerase II, second largest submit (RPB2). The PCR procedures followed Song \& Cui (2017) and Zhu et al. (2019). PCR products were purified and sequenced at the Beijing Genomics Institute with the same 
primers and the sequences were deposited in GenBank and listed in Table 1.

\section{Phylogenetic analyses}

In this study, 181 new sequences, viz. 46 ITS, 49 nLSU, 34 RPB2 and 52 TEF1, were generated (Table 1). To explore the phylogenetic position of Fuscoporia in Hymenochaetaceae, 90 sequences (not shown in Table 1 except for Fuscoporia) of representatives of 27 genera of Hymenochaetaceae were included in nLSU dataset (Fig. 1). The genus Fuscoporia was represented by 38 species and other genera were represented by a few known species (mainly the generic type). Oxyporus populinus (Schumach.) Donk and Hyphodontia pallidula (Bres.) J. Erikss. were used as outgroup taxa based on previous studies (Larsson et al. 2006, Zmitrovich \& Malysheva 2014, Zhou et al. 2016, Chen et al. 2019).

To explore the phylogenetic relationships to species-level of Fuscoporia, 133 sequences in 30 species (shown in Table 1) in the ITS+nLSU+RPB2+TEF1 datasets (Fig. 2) were downloaded from GenBank based on Chen \& Dai (2019) and Chen et al. (2019) and analysed. Coniferiporia weirii (Murrill) L.W. Zhou \& Y.C. Dai and Phellinidium fragrans (M.J. Larsen \& Lombard) Nuss were selected as outgroup for the ITS+nLSU+RPB2+TEF1 analysis, because they were shown to be sister groups of Fuscoporia based on the nLSU phylogenetic analysis (Fig. 1) and as outgroup in previous studies (Zhou et al. 2016, Chen et al. 2019). Sequences were aligned with BioEdit (Hall 1999) and the alignments generated in ClustalX were used to construct phylogenetic analyses (Thompson et al. 1997). GTR+I+G was the selected substitution model for each partition of the two alighments.

Maximum parsimony (MP) analysis was used for the nLSU and the ITS+nLSU+RPB2+TEF1 datasets in PAUP* 4.0b10 (Swofford 2002). All characters were equally weighted and gaps treated as missing data. Trees were inferred using the heuristic search option with tree bisection reconnection (TBR) branch swapping and 1000 random sequence additions. The maxtrees parameter was set to 5000, branches of zero length were collapsed, and all parsimonious trees were saved. Clade robustness was assessed by a bootstrap analysis with 1000 replicates (Felsenstein 1985). Descriptive tree statistics such as tree length (TL), consistency index (CI), retention index (RI), rescaled consistency index (RC), and homoplasy index (HI) were calculated (Swofford 2002).

Maximum likelihood (ML) methods were also used for both datasets. Substitution models suitable for each partition, including ITS and nLSU, and introns and codons of the RPB2 and TEF1 gene, were determined using the Akaike information criterion implemented in MrModeltest 2.3 (Posada \& Crandall 1998, Nylander 2004). RaxmlGUI 1.2 (Stamatakis 2006, Silvestro \& Michalak 2012) was used for ML analysis. All parameters in the ML analysis used default settings. Statistical support values were obtained using nonparametric bootstrapping with 1000 replicates. MP and ML methods were adopted to perform phylogenetic analysis of the two aligned datasets. The two phylogenetic methods produced a similar topology for each dataset, so, only the topology of the MP tree is presented along with statistical values of the MP/ML algorithm (simultaneous MP and ML not less than 50\%) at the nodes. DNA alignments have been deposited at TreeBase (25546).

The nLSU dataset comprised 92 sequences and an alignment of 1435 positions, of which 1026 were constant, 93 variables but parsimony-uninformative, and 316 parsimony-informative. Maximum Parsimony yielded four equally most parsimonious trees $(\mathrm{TL}=1878, \mathrm{CI}=0.325, \mathrm{RI}=$ $0.717, \mathrm{RC}=0.233, \mathrm{HI}=0.675)$. The four-gene dataset included sequences from 105 specimens representing 41 species of Fuscoporia and two species of related genera. This alignment contained 3686 sites: 900 positions from ITS, 1400 from nLSU, 821 from RPB2 and 566 from TEF1. In this aligment 2215 characters were constant, 180 variables but parsimony-uninformative, and 1291 parsimony-informative. MP analysis yielded four similar topologies $(\mathrm{TL}=6400, \mathrm{CI}=0.434, \mathrm{RI}=$ $0.837, \mathrm{RC}=0.363, \mathrm{HI}=0.566$ ). Maximum Likelihood analysis resulted in a similar consensus tree as the MP analysis in two phylogenetic analyses, so MP trees are shown here (Figs 1-2) and all the other topologies are provided as supplemental materials. 


\section{Results}

Fuscoporia is strongly supported (96/99) within the Hymenochaetaceae family by phylogenetic analysis inferred from the nLSU rDNA-based phylogeny (Fig. 1). The combined ITS, nLSU, RPB2, and TEF1 sequences (Fig. 2) including 41 species of Fuscoporia shows that nine new species formed nine independant lineages indicating that they are phylogenetically distinct from the species currently known in the genus. Two species, Fuscoporia bambusicola and F. roseocinerea, previously treated in Phellinus are nested in Fuscoporia. Six distinctive groups (highlighted in Fig. 2 ) are defined within Fuscoporia, viz. F. contigua group, $F$. ferrea group, $F$. ferruginosa group, $F$. gilva group, $F$. torulosa group, and $F$. viticola group. Three species, Fuscoporia acutimarginata, $F$. discipes and $F$. insolita, are nested in three subclades (Fig. 2) without enough support, and they do not belong to any distinct group.

Table 1 Species, specimens and GenBank accession number of sequences used in this study.

\begin{tabular}{|c|c|c|c|c|c|}
\hline \multirow{2}{*}{ Taxa } & \multirow{2}{*}{$\begin{array}{l}\text { Voucher } \\
\text { specimens }\end{array}$} & \multicolumn{4}{|c|}{ GenBank accession numbers } \\
\hline & & ITS & nLSU & RPB2 & TEF1 \\
\hline $\begin{array}{l}\text { Fuscoporia } \\
\text { acutimarginata }\end{array}$ & Dai 15137 & MH050751 & MH050765 & MN848788* & MN848821* \\
\hline F. acutimarginata & Dai 16892 & MH050752 & MH050766 & МH079393 & MN848822* \\
\hline F. americana & JV 1209/3-J & - & MG008466 & $\mathrm{v}$ & - \\
\hline F. americana & JV 1209/100 & KJ940022 & MG008467 & - & MH636384 \\
\hline F. americana & JV1309/13-J & - & MG008463 & - & MH636385 \\
\hline F. atlantica & SP 445618 & KP058515 & KP058517 & - & - \\
\hline F. atlantica & SP 465829 & KP058514 & KP058516 & - & - \\
\hline F. australasica & Dai 15625 & MN816726* & MN810018* & MN848775* & MN848829* \\
\hline F. australasica & Dai 15636 & MG008397 & MG008450 & MH079402 & MH636408 \\
\hline F. australasica & Dai 15659 & MG008398 & MG008451 & MH079403 & MH636409 \\
\hline F. australiana & Dai 18587A & MN816723* & MN810013* & MN848765* & MN848849* \\
\hline F. australiana & Dai 18672 & MN816703* & MN810014* & MN848766* & MN848848* \\
\hline F. australiana & Dai 18879 & MN816705* & MN810015* & MN848767* & MN848850* \\
\hline F. bambusae & Dai 16599 & MN816711* & MN809999* & - & MN848808* \\
\hline F. bambusae & Dai 16607 & MN816713* & MN810000* & MN848797* & MN848809* \\
\hline F. bambusae & Dai 16615 & MN816715* & MN810001* & - & MN848810* \\
\hline F. bambusicola & Cui 8692 & MN816739* & MT032486* & - & MN848813* \\
\hline F. callimorpha & JV 1408/11 & - & MN809991* & - & MN848839* \\
\hline F. callimorpha & Dai 17388 & MN121765 & MN121824 & - & - \\
\hline F. callimorpha & Doll 868 & MN816701* & MN809992* & - & MN848840* \\
\hline F. chinensis & Dai 15713 & MN816721* & MN810008* & MN848771* & MN848846* \\
\hline F. chinensis & Cui 11209 & MN121767 & MN121826 & MN159388 & - \\
\hline F. chinensis & Dai 17282 & MN816710* & MN810009* & MN848772* & MN848847* \\
\hline F. chrysea & JV 1607/106-J & MN816736* & MN810027* & MN848773* & MN848818* \\
\hline F. centroamericana & JV 1607/93 & MG008444 & MG008460 & - & MH636389 \\
\hline F. centroamericana & O 908267 & MG008443 & - & - & - \\
\hline F. contigua & Dai 16025 & MG008401 & MG008454 & МH079406 & MH636386 \\
\hline F. contigua & Dai 13567A & MG008402 & MG008455 & MN159386 & MN848817* \\
\hline F. contigua & Cui 9760 & - & MG478452 & - & - \\
\hline F. costaricana & JV 1407/92 & MG008446 & MG008461 & - & MH636400 \\
\hline F. costaricana & JV 1504/85 & MG008413 & MG478454 & - & MH636401 \\
\hline F. discipes & Wei 4947 & - & HQ328524 & - & - \\
\hline F. eucalypti & Dai 18634A & MN816729* & MN810020* & MN848777* & MN848830* \\
\hline F. eucalypti & Dai 18783 & MN816730* & MN810021* & MN848776* & MN848832* \\
\hline
\end{tabular}


Table 1 Continued.

\begin{tabular}{|c|c|c|c|c|c|}
\hline \multirow{2}{*}{ Taxa } & \multirow{2}{*}{$\begin{array}{c}\text { Voucher } \\
\text { specimens }\end{array}$} & \multicolumn{4}{|c|}{ GenBank accession numbers } \\
\hline & & ITS & nLSU & RPB2 & TEF1 \\
\hline F. eucalypti & Dai 18792 & MN816731* & MN810022* & MN848778* & MN848831* \\
\hline F. ferrea & JV 1606/2.2-J & KX961100 & KY189100 & MH079394 & MH636402 \\
\hline F. ferrea & MUCL 45984 & KX961112 & KY189112 & - & MH636403 \\
\hline F. ferrea & Cui 11801 & KX961101 & KY189101 & MN159387 & MN848823* \\
\hline F. formosana & TFRI 799 & - & AY059034 & - & - \\
\hline F. ferruginosa & JV 0408/28 & KX961103 & KY189103 & - & MH636397 \\
\hline F. ferruginosa & JV 1507/11-CN & MG008400 & MG008453 & MH079404 & MH636399 \\
\hline F. ferruginosa & Dai 13200 & MN816702* & MN809993* & MN848793* & MN848802* \\
\hline F. ferruginosa & Dai 16030 & MN816704 & MN809994 & MN848790 & MN848803 \\
\hline F. ferruginosa & Cui 9244 & MN816706 & MN809995 & MN848791 & MN848804 \\
\hline F. ferruginosa & JV 0509/151 & MN816707 & MN809996 & MN848792 & - \\
\hline F. gilva & Dai 17922 & - & MN810005* & - & - \\
\hline F. gilva & JV 1209/65 & MN816719* & MN810006* & MN848768* & MN848851* \\
\hline F. gilva & JV 0709/75 & MN816720* & MN810007* & - & MN848852* \\
\hline F. insolita & Spirin 5251 & KJ677113 & - & - & - \\
\hline F. insolita & Spirin 5208 & MN816724* & MN810016* & - & MN848800* \\
\hline F. karsteniana & Dai 16552 & MN816716* & MN810002* & MN848794* & MN848806* \\
\hline F. karsteniana & Dai 11403 & MN816717* & MN810003* & MN848795* & MN848807* \\
\hline F. karsteniana & Dai 15717 & MN816718* & MN810004* & - & MN848805* \\
\hline F. latispora & JV 1109/48 & MG008439 & MG008468 & MN848799* & MH636395 \\
\hline F. latispora & JV 0610/VII-Kout & MG008436 & MG008469 & - & MH636396 \\
\hline F. monticola & Dai 10909 & MG008410 & - & - & - \\
\hline F. monticola & Dai 11860 & MG008406 & MG008457 & - & MH636390 \\
\hline F. palomari & JV 1004/5-J & MN816737* & - & - & - \\
\hline F. palomari & JV 1305/3-J & MN816738* & MN810028* & - & MN848801* \\
\hline F. plumeriae & Dai 17814 & MN816714* & MN810011* & - & MN848845* \\
\hline F. plumeriae & Dai 18858 & MN816712* & MN810010* & MN848769* & MN848843* \\
\hline F. plumeriae & Dai 18820 & MN816722* & MN810012* & MN848770* & MN848844* \\
\hline F. punctatiformis & Dai 17443 & MH050755 & МH050764 & - & - \\
\hline F. punctatiformis & Doll\#872a & MH050753 & - & - & - \\
\hline F. ramulicola & Dai 15723 & MH050749 & MH050762 & MH079398 & MN848824* \\
\hline F. ramulicola & Dai 16155 & MH050750 & MH050763 & МH079399 & MN848825* \\
\hline F. rhabarbarina & Cui 11357 & - & MN810034* & MN848782* & MN848837* \\
\hline F. rhabarbarina & Dai 16226 & MN816743* & MN810035* & MN848784* & MN848838* \\
\hline F. rhabarbarina & Dai 16550 & MN816744* & MN810036* & MN848785* & MN848836* \\
\hline F. roseocinerea & JV 1407/84 & MN816740* & MN810030* & MN848774* & MN848819* \\
\hline F. roseocinerea & JV 1408/31 & MN816741* & MN810031* & - & - \\
\hline F. roseocinerea & JV 1109/78-J & MN816742* & MN810032* & - & MN848820* \\
\hline F. rufitincta & JV 1008/25 & KJ940029 & KX058575 & - & - \\
\hline F. rufitincta & JV 0904/142 & KJ940030 & KX058574 & - & - \\
\hline F. senex & Dai 15775 & MN816746* & MN810038* & MN848787* & MN848834* \\
\hline F. senex & Dai 17043 & MN816747* & MN810039* & MN848786* & MN848835* \\
\hline F. senex & MEL2382630 & KP012992 & - & - & - \\
\hline F. senex & KAUNP MK41 & KP794600 & - & - & - \\
\hline F. septiseta & Dai 12820 & MG008405 & MN810033* & - & MH636394 \\
\hline F. septiseta & JV 0509/78 & MG008404 & - & - & - \\
\hline F. septiseta & TENN 046808 & MG008434 & MG570133 & - & - \\
\hline
\end{tabular}


Table 1 Continued.

\begin{tabular}{|c|c|c|c|c|c|}
\hline \multirow{2}{*}{ Taxa } & \multirow{2}{*}{$\begin{array}{l}\text { Voucher } \\
\text { specimens }\end{array}$} & \multicolumn{4}{|c|}{ GenBank accession numbers } \\
\hline & & ITS & nLSU & RPB2 & TEF1 \\
\hline F. setifera & Dai 15710 & MH050758 & MH050767 & MN159390 & MN848841* \\
\hline$F$. setifera & Dai 15706 & МH050759 & МH050769 & MN159391 & MN848842* \\
\hline F. shoreae & Dai 17800 & MN816733* & MN810024* & - & MN848814* \\
\hline F. shoreae & Dai 17806 & MN816734* & MN810025* & - & MN848815* \\
\hline F. shoreae & Dai 17818 & MN816735* & MN810026* & - & MN848816* \\
\hline F. sinica & Dai 15468 & MG008412 & MG008459 & - & MH636392 \\
\hline F. sinica & Dai 15489 & MG008407 & MG008458 & MN848798* & MH636393 \\
\hline F. sinica & Cui 9454 & MG008411 & - & - & MH636391 \\
\hline F. subchrysea & Dai 16201 & MN816708* & MN809997* & MN848796* & MN848811* \\
\hline F. subchrysea & Dai 17656 & MN816709* & MN809998* & - & MN848812* \\
\hline F. subferrea & Dai 16326 & KX961097 & KY053472 & МH079400 & MN848826* \\
\hline F. subferrea & Dai 16327 & KX961098 & KY053473 & МH079401 & - \\
\hline F. torulosa & JV $1405 / 2$ & KX961106 & KY189106 & MN848779* & MH636405 \\
\hline F. torulosa & JV 1312/19-Kout & KX961107 & KY189107 & MN848780* & MH636406 \\
\hline F. torulosa & Dai 15518 & MN816732* & MN810023* & MN848781* & MN848827* \\
\hline F. viticola & JV 0911/6 & KX961110 & - & - & - \\
\hline F. viticola & He 2081 & MN121770 & MN121829 & - & - \\
\hline F. viticola & He 2123 & MN816725* & MN810017* & - & - \\
\hline F. wahlbergii & JV 1312/20-Kout & MN816727* & MG008462 & - & - \\
\hline F. wahlbergii & Dai 18673 & - & MN810019* & - & MN848828* \\
\hline F. wahlbergii & JV 0709/169-J & MN816728* & - & - & - \\
\hline F. wahlbergii & $89-922$ & - & AF311045 & - & - \\
\hline F. yunnanensis & Cui 8182 & MH050756 & MN810029* & MN848789* & - \\
\hline F. yunnanensis & Dai 15637 & MH050757 & MH050768 & - & - \\
\hline \multicolumn{6}{|l|}{ Outgroups } \\
\hline Coniferiporia weirii & CFS 504 & AY829341 & AY829345 & - & - \\
\hline $\begin{array}{l}\text { Phellinidium } \\
\text { fragrans }\end{array}$ & CBS 202.90 & AY558619 & AY059027 & - & - \\
\hline
\end{tabular}

* Newly generated sequences for this study. New species and new combinations are in bold

\section{Taxonomy}

Fuscoporia australasica Q. Chen, F. Wu \& Y.C. Dai, sp. nov.

Figs $3 a, b, 4$

MycoBank number: MB 833958; Facesoffungi number: FoF 07995.

Etymology - Australasica (Lat.): referring to the species found in Southern Asia.

Holotype - China, Yunnan Province, Jingdong County, Ailaoshan Nature Reserve, on dead angiosperm tree, 24 Aug 2015, Y.C. Dai 15636 (BJFC 019740).

Basidiocarps - Perennial, pileate, solitary to imbricate, without odor or taste when fresh, hard corky when dry. Pilei mostly dimidiate, rarely circular, projecting up to $6 \mathrm{~cm}$ long, $8 \mathrm{~cm}$ wide and $1.8 \mathrm{~cm}$ thick at the base. Pilear surface reddish brown, concentrically sulcate with zones, velutinate to glabrous; margin obtuse to slightly acute, yellowish brown, up to $5 \mathrm{~mm}$ wide. Pore surface honey-yellow to olivaceous buff, glancing, margin narrow, yellowish, up to $2 \mathrm{~mm}$ wide; pores circular, 6-8 per mm; dissepiments thin, entire, abundant hymenial setae in tube cavities (under anatomical lens). Context clay-buff, hard corky, about $1 \mathrm{~mm}$ thick. Tubes concolorous with pores, hard corky, up to $1.7 \mathrm{~cm}$ long.

Hyphal structure - Hyphal system dimitic; generative hyphae simple septate; tissue darkening but otherwise unchanged in $\mathrm{KOH}$. 


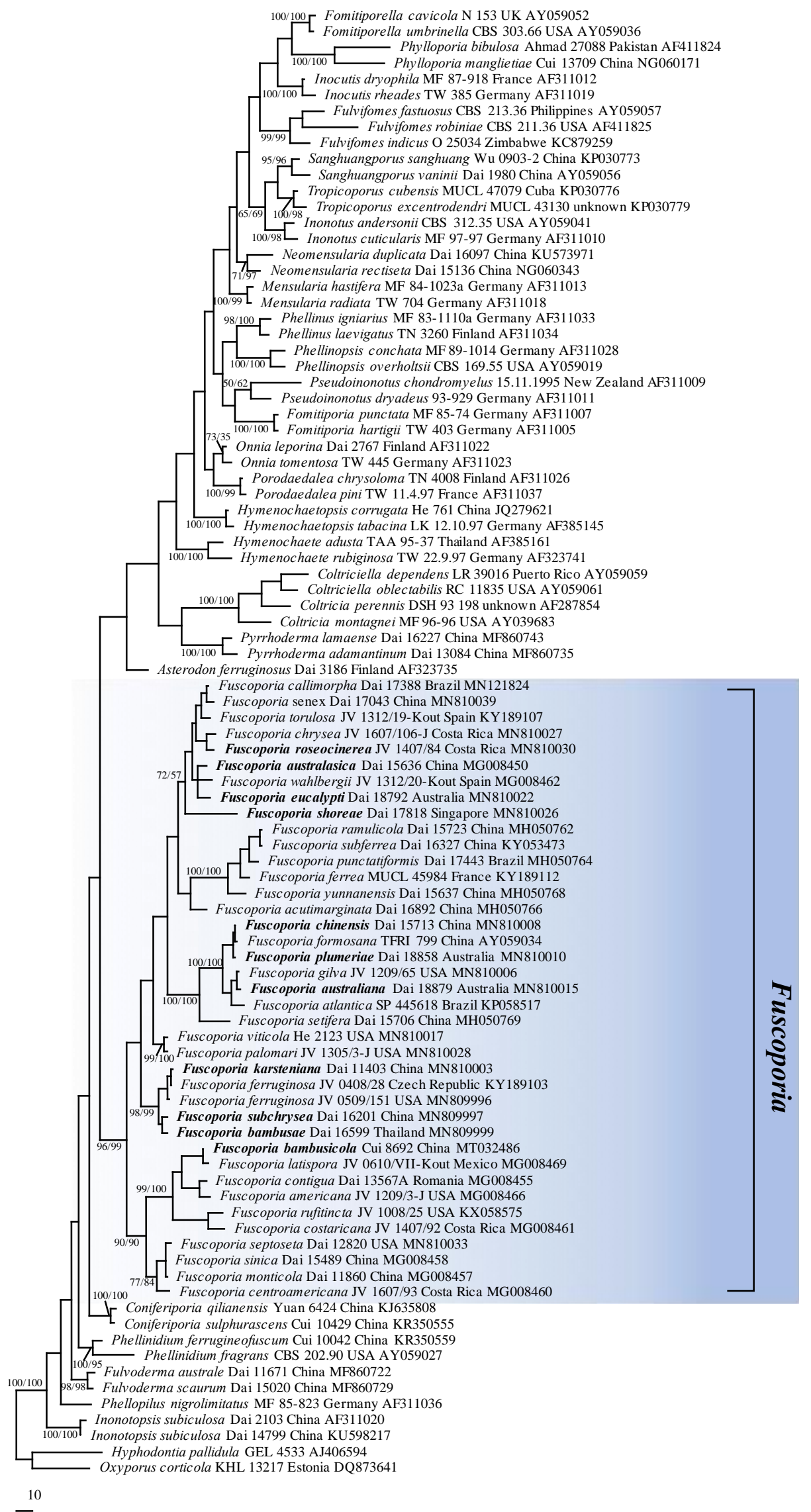

Figure 1 - Phylogenetic position of Fuscoporia within the Hymenochaetaceae inferred from the nLSU rDNA dataset. The topology is from one of the four MP trees. Statistical values (MP/ML) are indicated for each node that received bootstrap support from ML and MP $\geq 50 \%$. Names of new species are in bold. 


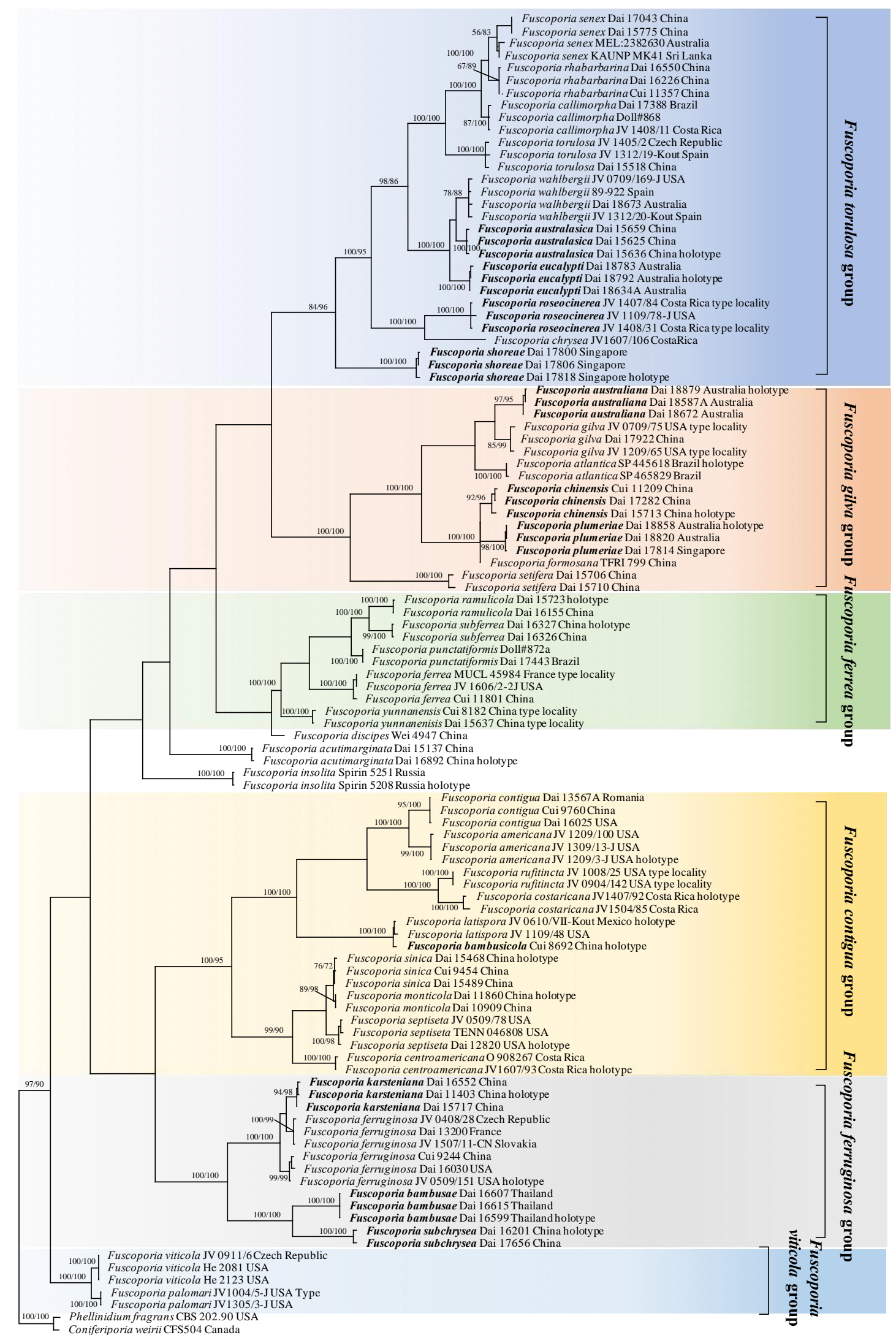

10

Figure 2 - Phylogeny of Fuscoporia species inferred from ITS+28S+RPB2+TEF1 dataset. The topology is one of the four MP trees. Statistical values (MP/ML) are indicated for each node that received bootstrap support from ML and MP $\geq 50 \%$. Names of new species are in bold. 
Context - Generative hyphae rare, hyaline, thin- to slightly thick-walled, unbranched, frequently simple septate, $2-2.5 \mu \mathrm{m}$ in diam.; skeletal hyphae dominant, rust-brown, thick-walled with a medium to wide lumen, unbranched, occasionally septate, straight, regularly arranged, 3-3.5 $\mu \mathrm{m}$ in diam.

Tubes - Generative hyphae rare, mostly present at dissepiment edges and subhymenium, hyaline, thin-walled, frequently branched and simple septate, 1.5-2.5 $\mu \mathrm{m}$ in diam., some of them encrusted at dissepiment edges and in the hymenium; skeletal hyphae dominant, yellowish brown, thick-walled with a medium to wide lumen, frequently septate, more or less straight, subparallel along the tubes, 2.5-3.5 $\mu \mathrm{m}$ in diam. Hymenial setae subulate, occasionally hooked, mostly originating from tramal hyphae, dark brown, thick-walled, 30-45 $\times 6-9 \mu \mathrm{m}$; fusoid cystidioles hyaline and thin-walled, 9.5-12 $\times 4-5.5 \mu \mathrm{m}$; basidia short clavate to barrel-shaped, with four sterigmata and a simple septum at the base, $9-11 \times 5-6.5 \mu \mathrm{m}$; basidioles dominating the hymenium, in shape similar to basidia, but slightly smaller.

Spores - Basidiospores broadly ellipsoid to subglobose, hyaline, thin-walled, smooth, IKI-, $\mathrm{CB}-$, some of them bearing a guttule, $(3.8-) 4-5 \times(3.2-) 3.3-4(-4.5) \mu \mathrm{m}, \mathrm{L}=4.40 \mu \mathrm{m}, \mathrm{W}=3.88$ $\mu \mathrm{m}, \mathrm{Q}=1.12-1.15(\mathrm{n}=90 / 3)$.

Other materials examined (paratypes) - China, Hainan Province, Lingshui County, Diaoluoshan Forest Park, on fallen angiosperm trunk, 13 Nov 2015, Y.C. Dai 16127 (BJFC 020221); Yunnan Province, Jingdong County, Ailaoshan Nature Reserve, on angiosperm stump, 15 Oct 2013, Y.C. Dai 13552 (BJFC 015014), 24 Aug 2015, Y.C. Dai 15635 (BJFC 019739); on dead angiosperm tree, 24 Aug 2015, Y.C. Dai 15625 (BJFC 019729); Yongde County, Daxueshan Nature Reserve, on rotten angiosperm stump, 27 Aug 2015, Y.C. Dai 15659 (BJFC 019763). Vietnam, Lam Dong Province, Lac Duong District, Bidoup Nui Ba National Park, on dead angiosperm tree, 15 Oct 2017, Y.C. Dai 18362 (BJFC 025885).

Note - Fuscoporia australasica grows on angiosperm wood in tropical Asia and is characterized by pileate basidiocarps, small pores (6-8 per $\mathrm{mm})$, occasionally hooked hymenial setae and broadly ellipsoid to subglobose basidiospores, 4-5 $\times 3.2-4 \mu \mathrm{m}$. In our phylogeny, three specimens of Fuscoporia australasica form a lineage with strong support (100/100, Fig. 2). Fuscoporia australasica is closely related to $F$. eucalypti sp. nov. and $F$. wahlbergii (Fr.) $\mathrm{T}$. Wagner \& M. Fisch. (Figs 1-2). Morphologically, these species share the hooked hymenial setae and broadly ellipsoid to subglobose basidiospores; but basidiospores are wider in $F$. eucalypti than in $F$. australasica $(4-4.5 \mu \mathrm{m}$ vs. 3.3-4 $\mu \mathrm{m})$ and $F$. wahlbergi has globose spores $(3.5-4 \mu \mathrm{m}$, Reid 1975).

Fuscoporia australiana Q. Chen, F. Wu \& Y.C. Dai, sp. nov.

Figs $3 \mathrm{c}, 5$

MycoBank number: MB 833960; Facesoffungi number: FoF 07996.

Etymology - Australiana (Lat.): referring to the species found in Australia.

Holotype - Australia, Sydney, Sydney Botanical Garden, on stump of Combretum, 20 May 2018, Y.C. Dai 18879 (BJFC 027347, isotype in MEL).

Basidiocarps - Usually annual, occasionally biennial, pileate, solitary to imbricate, sometimes effused-reflexed, without odor or taste and corky when fresh, becoming hard corky and light-weight when dry. Pilei mostly dimidiate to conchate, sometimes laterally fused, projecting up to $5 \mathrm{~cm}$ long, $10 \mathrm{~cm}$ wide and $1.5 \mathrm{~cm}$ thick at the base. Pilear surface olivaceous buff to clay-buff, indistinctly concentrically sulcate with zones, hispid to rugose; margin obtuse, honey-yellow. Pore surface grayish brown to olivaceous buff, slightly glancing; margin narrow, honey-yellow, paler than pore surface, up to $1 \mathrm{~mm}$ wide; pores more or less round, 7-9 per $\mathrm{mm}$; dissepiments thin, entire to slightly lacerate, sometimes sinuous or irregular, abundant setae seen in tube cavities (under anatomical lens). Context honey-yellow to curry-yellow, hard corky, zonate, up to $0.5 \mathrm{~cm}$ thick. Tubes olivaceous buff, paler than pore surface, hard corky up to $1 \mathrm{~cm}$ long.

Context - Generative hyphae rare, hyaline, thin-walled, occasionally branched, frequently simple septate, 2-3 $\mu \mathrm{m}$ in diam.; skeletal hyphae dominant, yellowish brown, thick-walled with a wide lumen, unbranched, aseptate, straight, regularly arranged, 3.5-5 $\mu \mathrm{m}$ in diam. 
Tubes - Generative hyphae rare, mostly present at dissepiment edges and subhymenium, hyaline, thin-walled, frequently branched and septate, $1.5-2.5 \mu \mathrm{m}$ in diam., some of them encrusted at dissepiment edges and in the hymenium; skeletal hyphae dominant, yellowish brown, thickwalled with a wide lumen, unbranched, aseptate, straight, subparallel along the tubes, 2.5-3.5 $\mu \mathrm{m}$ in diam. Setae frequent, mostly originating from tramal hyphae, ventricose to subulate, dark brown, thick-walled, 20-35 $\times 5-7 \mu \mathrm{m}$; fusoid cystidioles hyaline, thin-walled, sometimes bearing crystals, 15-22 $\times 3-4 \mu \mathrm{m}$; basidia short clavate to barrel-shaped, with four sterigmata and a simple septum at the base, $12-16 \times 4-6 \mu \mathrm{m}$; basidioles dominating in hymenium, in shape similar to basidia, but slightly smaller.

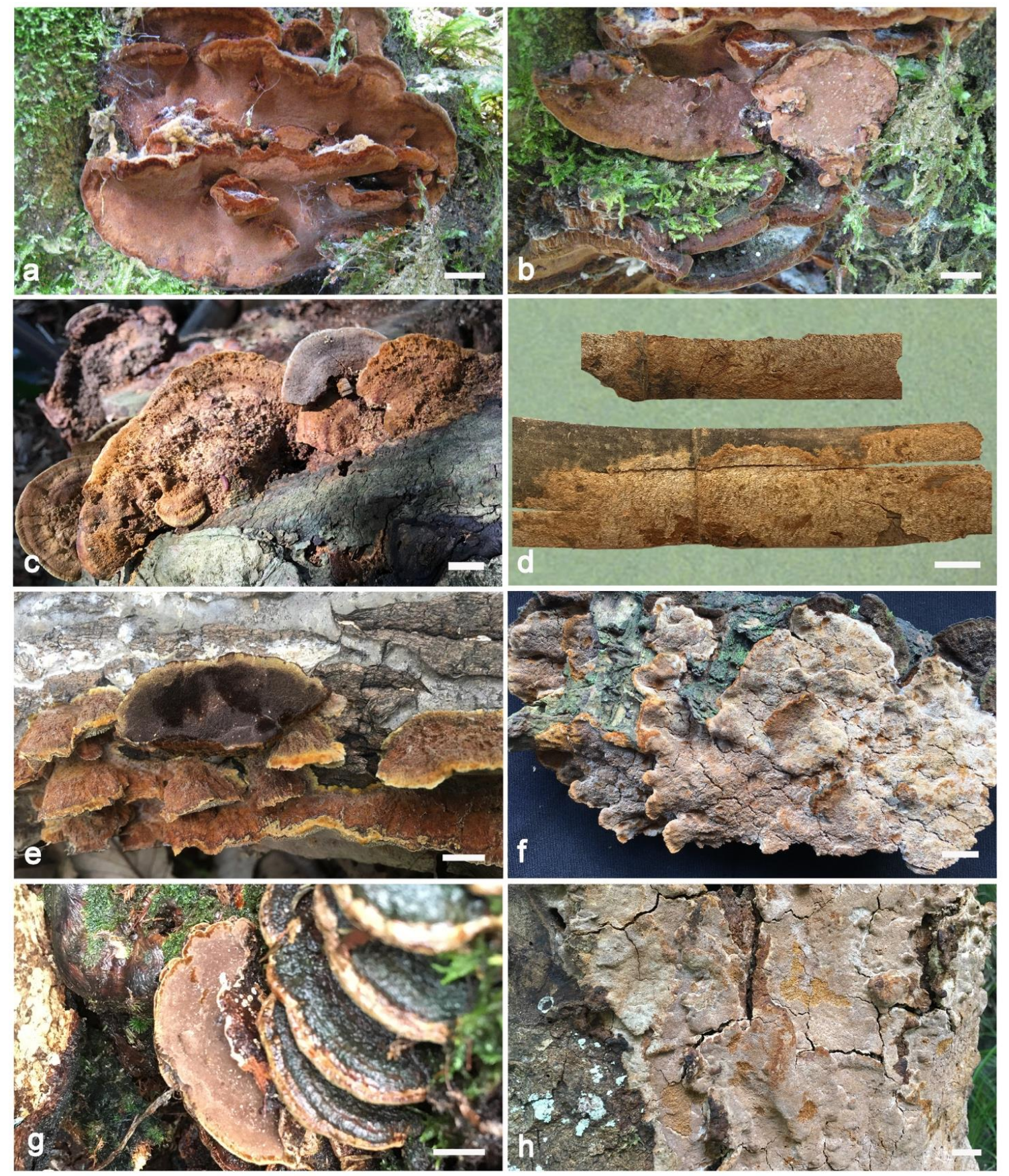

Figure 3 - Basidiocarps of Fuscoporia species. a-b Fuscoporia australasica (paratype, Dai 15625). c Fuscoporia australiana (holotype, Dai 18879). d Fuscoporia bambusae (holotype, Dai 16599). e-f Fuscoporia chinensis (e paratype, Dai 17282, f paratype, Dai 17583). g Fuscoporia eucalypti (paratype, Dai 18642A). h Fuscoporia karsteniana (paratype, Dai 17925). Scale Bars $=10 \mathrm{~mm}$. 

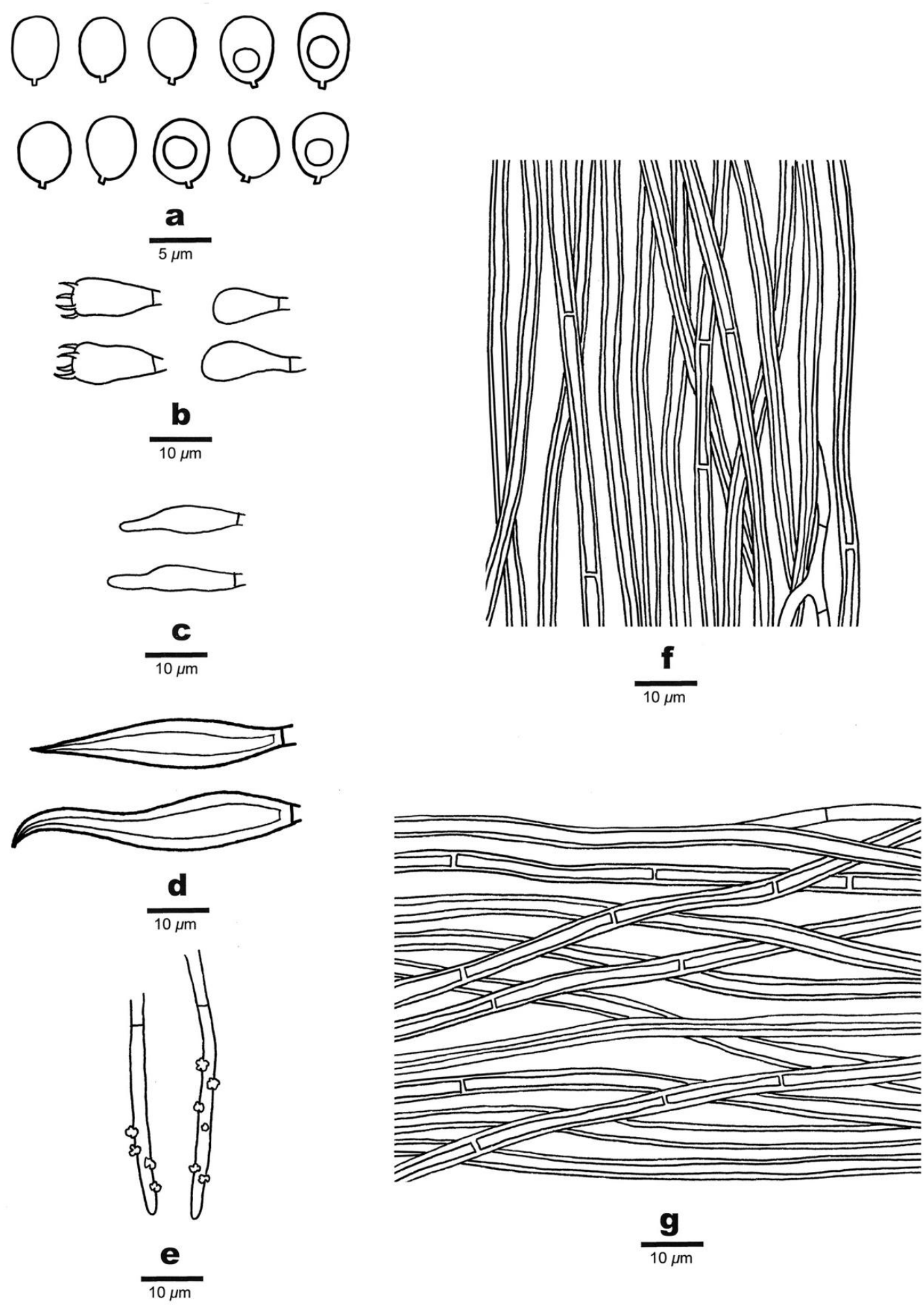

Figure 4 - Microscopic structures of Fuscoporia australasica (holotype, Dai 15636). a Basidiospores. b Basidia and basidioles. c Cystidioles. d Hymenial setae. e Generative hyphae at dissepiment edge. f Hyphae from trama. g Hyphae from context.

Hyphal structure - Hyphal system dimitic; generative hyphae simple septate; tissue darkening but otherwise unchanged in $\mathrm{KOH}$.

Spores - Basidiospores ellipsoid, hyaline, thin-walled, smooth, IKI-, CB-, usually bearing a small guttule, (3.8-)4-4.8(-5) $\times(2-) 2.5-3(-3.5) \mu \mathrm{m}, \mathrm{L}=4.28 \mu \mathrm{m}, \mathrm{W}=2.73 \mu \mathrm{m}, \mathrm{Q}=1.56-1.64(\mathrm{n}$ $=60 / 2$ ).

Other materials examined (paratypes) - Australia, Melbourne, Dandenong Ranges Botanical 
Garden, on fallen trunk of Eucalyptus, 12 May 2018, Y.C. Dai 18672 (BJFC 027141); Royal Botanic Gardens, on angiosperm stump, 8 May 2018, Y.C. Dai 18587A (BJFC 027056).

Note - Fuscoporia australiana was discovered in Australia, and the species is characterized by the annual to biennial, pileate basidiocarps with indistinctly concentrically sulcate, hispid to rugose pileal surface, small pores (7-9 per mm), ellipsoid basidiospores measuring 4-4.8 $\times$ 2.5-3 $\mu \mathrm{m} . F$. atlantica Motato-Vásq., R.M. Pires \& Gugliotta, F. chinensis sp. nov., F. formosana (T.T. Chang \& W.N. Chou) T. Wagner \& M. Fisch., F. gilva and F. plumeriae sp. nov. clustered together with $F$. australiana into a group with strong support (100/100, Figs 1-2). All these species share similar morphological characteristics as effused-reflexed to pileate basidiocarps with lacerate dissepiments and ellipsoid basidiospores. However, they formed six independent lineages in our phylogeny (Fig. 2). Morphologically, F. atlantica distinguishes itself from $F$. australiana by dark brown crusted pilear surface, hooked hymenial setae and wider basidiospores (3-3.5 $\mu \mathrm{m}$ vs. 2.5-3 $\mu \mathrm{m}$, Pires et al. 2015). Both, F. australiana and F. plumeriae occur in Australia, but $F$. plumeriae has smaller basidiospores measuring 3-3.8 $\times 2.2-2.8 \mu \mathrm{m}$. $F$. chinensis differs from $F$. australiana by its septate hymenial setae and smaller basidiospores $(3-4 \times 2-2.5 \mu \mathrm{m}$ vs. $4-4.8 \times 2.5-3 \mu \mathrm{m}) . F$. gilva is different from $F$. australiana by the presence of lacerate to dentate dissepiments, septate skeletal hyphae and shorter basidiospores (3.3-4.2 $\mu \mathrm{m}$ vs. 4-4.8 $\mu \mathrm{m}$, Dai 2010). F. formosana is distinguished from $F$. australiana by larger pores (3-5 per $\mathrm{mm}$ ) and smaller basidiospores measuring 3.5-4 × 1.5-2.5 $\mu \mathrm{m}$ (Chang \& Chou 1998, Ryvarden 2005). Both $F$. australiana and $F$. eucalipti sp. nov. are from Australia and can grow on Eucalyptus, but the latter differs from the former by hooked setae and sugbglobose basidiospores which are distinctly wider (4-4.5 $\mu \mathrm{m}$ in $F$. eucalipti vs. 2.5-3 $\mu \mathrm{m}$ in F. australiana). In addition, they are not phylogenetically related (Fig. 2).

Fuscoporia bambusae Q. Chen, F. Wu \& Y.C. Dai, sp. nov.

Figs $3 d, 6$

MycoBank number: MB 833963; Facesoffungi number: FoF 07997.

Etymology - Bambusae (Lat.): referring to the species growing on Bambusaceae.

Holotype - Thailand, Rai Empress, Dowager University Campus, on rotten bamboo, $21 \mathrm{Jul}$ 2016, Y.C. Dai 16599 (BJFC 022710).

Basidiocarps - Annual, resupinate, inseparable, without odor or taste when fresh, corky and light-weight when dry, up to $15 \mathrm{~cm}$ long, $3 \mathrm{~cm}$ wide and less than $1 \mathrm{~mm}$ thick at centre. Pore surface grayish brown, more or less fawn, uncracked when dry, sterile margin curry-yellow, paler than pore surface, usually with abundant mycelial setae, up to $2 \mathrm{~mm}$ wide; pores more or less circular, sometimes sinuous or irregular, 5-7 per $\mathrm{mm}$; dissepiments thin, entire to slightly lacerate, abundant hymenial setae seen in tube cavities (under anatomical lens). Subiculum fawn, corky, thin to almost lacking, up to $0.1 \mathrm{~mm}$ thick. Tubes honey-yellow, paler contrasting with subiculum, hard corky, up to $0.9 \mathrm{~mm}$ long.

Hyphal structure - Hyphal system dimitic; generative hyphae simple septate; tissue darkening but otherwise unchanged in $\mathrm{KOH}$.

Subiculum - Generative hyphae very rare, hyaline, thin-walled, occasionally branched, frequently simple septate, $2.5-3.8 \mu \mathrm{m}$ in diam.; skeletal hyphae dominant, rust-brown, thick-walled with a medium to wide lumen, unbranched, aseptate, flexuous, interwoven, 3-3.8 $\mu \mathrm{m}$ in diam.; mycelial setae frequent, dark reddish brown, thick-walled, septate, tapering to apex, present in the subiculum and in the rotten bamboo cavities, sometimes locally abundant, often in bundles, up to $240 \mu \mathrm{m}$ long and 5-9 $\mu \mathrm{m}$ in the widest part.

Tubes - Generative hyphae rare, mostly present at dissepiment edges and subhymenium, hyaline, thin-walled, frequently branched and simple septate, 2-3.5 $\mu \mathrm{m}$ in diam, some of them encrusted at dissepiment edges and in hymenium; skeletal hyphae dominant, yellowish brown, thick-walled with a narrow to medium lumen, unbranched, aseptate, flexuous, interwoven, 2.8-4 $\mu \mathrm{m}$ in diam. Hymenial setae frequent, narrowly subulate, mostly originating from tramal hyphae, dark brown, thick-walled, occasionally septate, 45-96 × 5-9 $\mu \mathrm{m}$; fusoid cystidioles frequent, hyaline and thin-walled, $14-23 \times 3-4.2 \mu \mathrm{m}$; basidia short clavate to barrel-shaped, with four 
sterigmata and a simple septum at the base, occasionally bearing a medium size guttule, $12-16 \times$ 4.5-7.2 $\mu \mathrm{m}$; basidioles dominating in hymenium, barrel-shaped, smaller than basidia.

Spores - Basidiospores ellipsoid, hyaline, thin-walled, smooth, usually glued in tetrads, bearing a small guttule, IKI-, CB-, (4.2-)4.3-5.3(-5.8) $\times(2.7-) 2.8-3.6(-3.8) \mu \mathrm{m}, \mathrm{L}=4.87 \mu \mathrm{m}, \mathrm{W}$ $=3.24 \mu \mathrm{m}, \mathrm{Q}=1.47-1.54(\mathrm{n}=60 / 2)$.
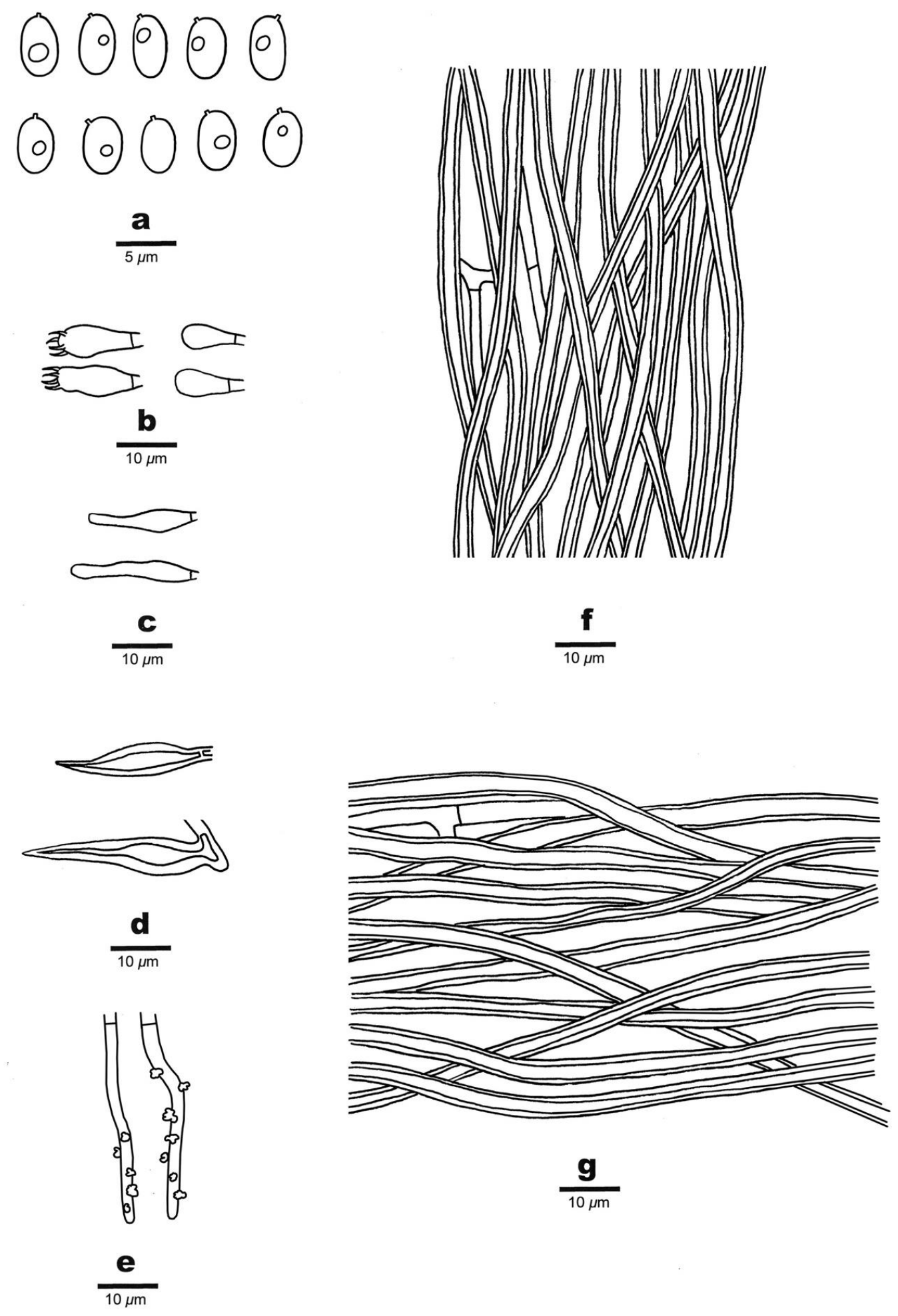

Figure 5 - Microscopic structures of Fuscoporia australiana (holotype, Dai 18879). a Basidiospores. b Basidia and basidioles. c Cystidioles. d Hymenial setae. e Generative hyphae at dissepiment edge. f Hyphae from trama. g Hyphae from context. 


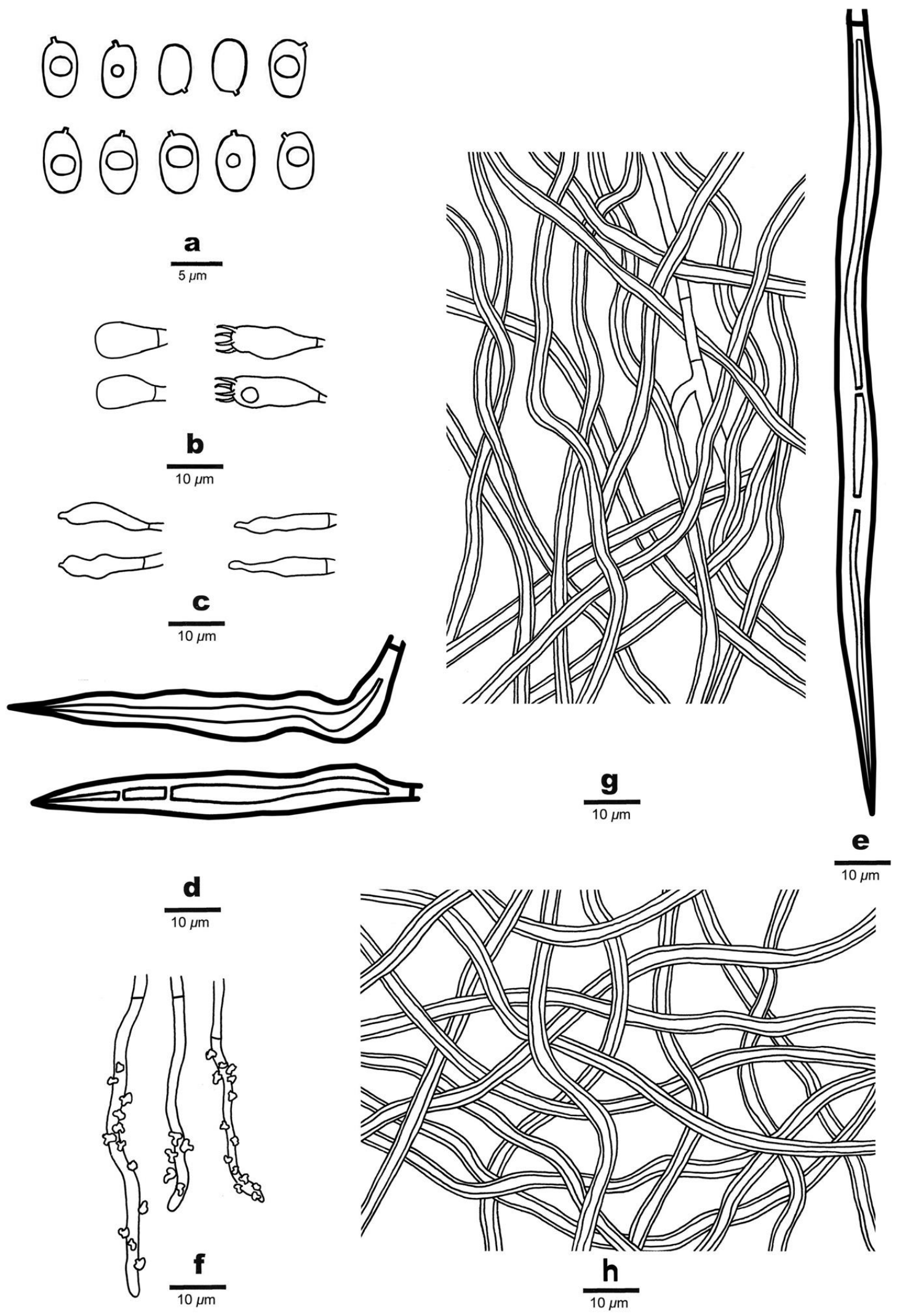

Figure 6 - Microscopic structures of Fuscoporia bambusae (holotype, Dai 16599). a Basidiospores. b Basidia and basidioles. c Cystidioles. d Hymenial setae. e Mycelial setae. f Generative hyphae at dissepiment edge. g Hyphae from trama. h Hyphae from subiculum.

Other materials examined (paratypes) - Thailand, Rai Empress, Dowager University Campus, on rotten bamboo, $21 \mathrm{Jul}$ 2016, Y.C. Dai 16607 (BJFC 022718); on dead bamboo, 21 Jul 2016, Y.C. Dai 16615 (BJFC 022725). 
Note - Fuscoporia bambusae is a tropical species growing on bamboo, differs from other species in Fuscoporia by its septate hymenial setae and mycelial setae. Three species of Fuscoporia grow on bamboo, $F$. bambusae, $F$. bambusicola, and $F$. subchrysea, they share resupinate basidiocarps and presence of mycelial setae; but $F$. bambusicola can be easily distinguished from $F$. bambusae by its larger pores (3-5 per mm, Zhou \& Jia 2010); F. subchrysea is closely related phylogenetically to $F$. bambusae (Figs $1-2$ ), but differs by its smaller pores (8-9 per mm) and shorter basidiospores (3.8-4.4 $\mu \mathrm{m}$ long).

Fuscoporia chinensis Q. Chen, F. Wu \& Y.C. Dai, sp. nov.

Figs $3 e, f, 7$

MycoBank number: MB 833956; Facesoffungi number: FoF 07998.

Etymology - Chinensis (Lat.): referring to the species found in China.

Holotype - China, Yunnan Province, Binchuan County, Jizushan Park, on fallen angiosperm branch, 30 Aug 2015, Y.C. Dai 15713 (BJFC 019817).

Basidiocarps - Annual, effused-reflexed to pileate, broadly attached, imbricate, without odor or taste and corky when fresh. Pilei dimidiate or conchate, often laterally fused, projecting up to 2 $\mathrm{cm}$ long, $5 \mathrm{~cm}$ wide and $5 \mathrm{~mm}$ thick at the base. Pilear surface yellowish brown to dark reddish, indistinctly concentrically sulcate, velutinate to rugose with age; margin obtuse, yellowish brown. Pore surface grayish brown to dark reddish brown, glancing; margin distinct, yellowish, paler than pore surface, up to $2 \mathrm{~mm}$ wide; pores circular to angular, 7-8 per $\mathrm{mm}$; dissepiments thin, slightly lacerate, abundant setae seen in tube cavities (under anatomical lens). Context yellowish brown, corky, up to $2 \mathrm{~mm}$ thick. Tubes yellowish brown, paler than context, corky, up to $3 \mathrm{~mm}$ long.

Hyphal structure - Hyphal system dimitic; generative hyphae simple septate; tissue darkening but otherwise unchanged in $\mathrm{KOH}$.

Context - Generative hyphae rare, hyaline, thin-walled, occasionally branched and simple septate, 2.5-4 $\mu \mathrm{m}$ in diam.; skeletal hyphae dominant, yellowish brown, thick-walled with a wide lumen, unbranched, aseptate, interwoven, $3.5-5 \mu \mathrm{m}$ in diam.

Tubes - Generative hyphae common, hyaline, thin-walled, frequently simple septate, occasionally branched, 2-4 $\mu \mathrm{m}$ in diam., some of them encrusted at dissepiment edges; skeletal hyphae dominant, yellowish brown, thick-walled with a wide lumen, unbranched, aseptate, straight, subparallel along the tubes, $3-4.5 \mu \mathrm{m}$ in diam. Hymenial setae mostly originating from tramal hyphae, subulate, frequently septate, dark brown, thick-walled, 20-40 $\times 4-8 \mu \mathrm{m}$; fusoid cystidioles frequent, hyaline, thin-walled, sometimes covered with crystals, 14-20 × 4-6 $\mu \mathrm{m}$; basidia short clavate to barrel-shaped, with four sterigmata and a simple septum at the base, 10-14 $\times 4-6 \mu \mathrm{m}$; basidioles in shape similar to basidia, but slightly smaller.

Spores - Basidiospores ellipsoid, hyaline, thin-walled, smooth, sometimes bearing a small guttule, IKI-, CB-, (2.9-)3-4(-4.3) x(1.8-)2-2.5(-2.8) $\mu \mathrm{m}, \mathrm{L}=3.55 \mu \mathrm{m}, \mathrm{W}=2.26 \mu \mathrm{m}, \mathrm{Q}=1.42-$ $1.65(\mathrm{n}=90 / 3)$.

Other materials examined (paratypes) - China, Hainan Province, Lingshui County, Diaoluoshan Forest Park, on fallen angiosperm branch, 13 Nov 2015, Y.C. Dai 16096 (BJFC 020189); Y.C. Dai 16119 (BJFC 020212); Heilongjiang Province, Heihe, Shengshan Nature Reserve, on fallen trunk of Quercus, 25 Aug 2014, Y.C. Dai 14246 (BJFC 017737); Hubei Province, Xiangfan, Xiangyang District, on fallen trunk of Castanea, 17 Oct 2016, Y.C. Dai 17282 (BJFC 023381); Wufeng County, Chaibuxi Park, on dead angiosperm tree, 14 Aug 2017, Y.C. Dai 17926 (BJFC 025455), Y.C. Dai 17936 (BJFC 025465), on dead tree of Prunus, 14 Aug 2017, Y.C. Dai 17913 (BJFC 025442); Houhe Nature Reserve, on angiosperm branch, 16 Aug 2017, Y.C. Dai 17960 (BJFC 025489); Y.C. Dai 17961 (BJFC 025490); Shanxi Province, Pingli County, Hualongshan Nature Reserve, on dead angiosperm tree, 14 Sept 2013, B.K. Cui 11209 (BJFC 015324); Sichuan Province, Qionglai County, Tiantaishan Forest Park, on dead angiosperm tree, 23 Oct 2012, B.K. Cui 10872 (BJFC 013794); Yunnan Province, Baoshan, Longyang District, Baihualing, on stump of angiosperm tree, 30 Nov 2015, Y.C. Dai 16386 (BJFC 020474); Nanhua County, Dazhongshan Nature Reserve, on dead angiosperm tree, 14 Jul 2013, B.K. Cui 11117 (BJFC 015232); Xinping County, Shimenxia Park, on stump of Alnus, 16 Jun 2017, Y.C. Dai 17583 
(BJFC 025115); Yongde County, Daxueshan Nature Reserve, on rotten angiosperm wood, 28 Aug 2015, Y.C. Dai 15681 (BJFC 019785).
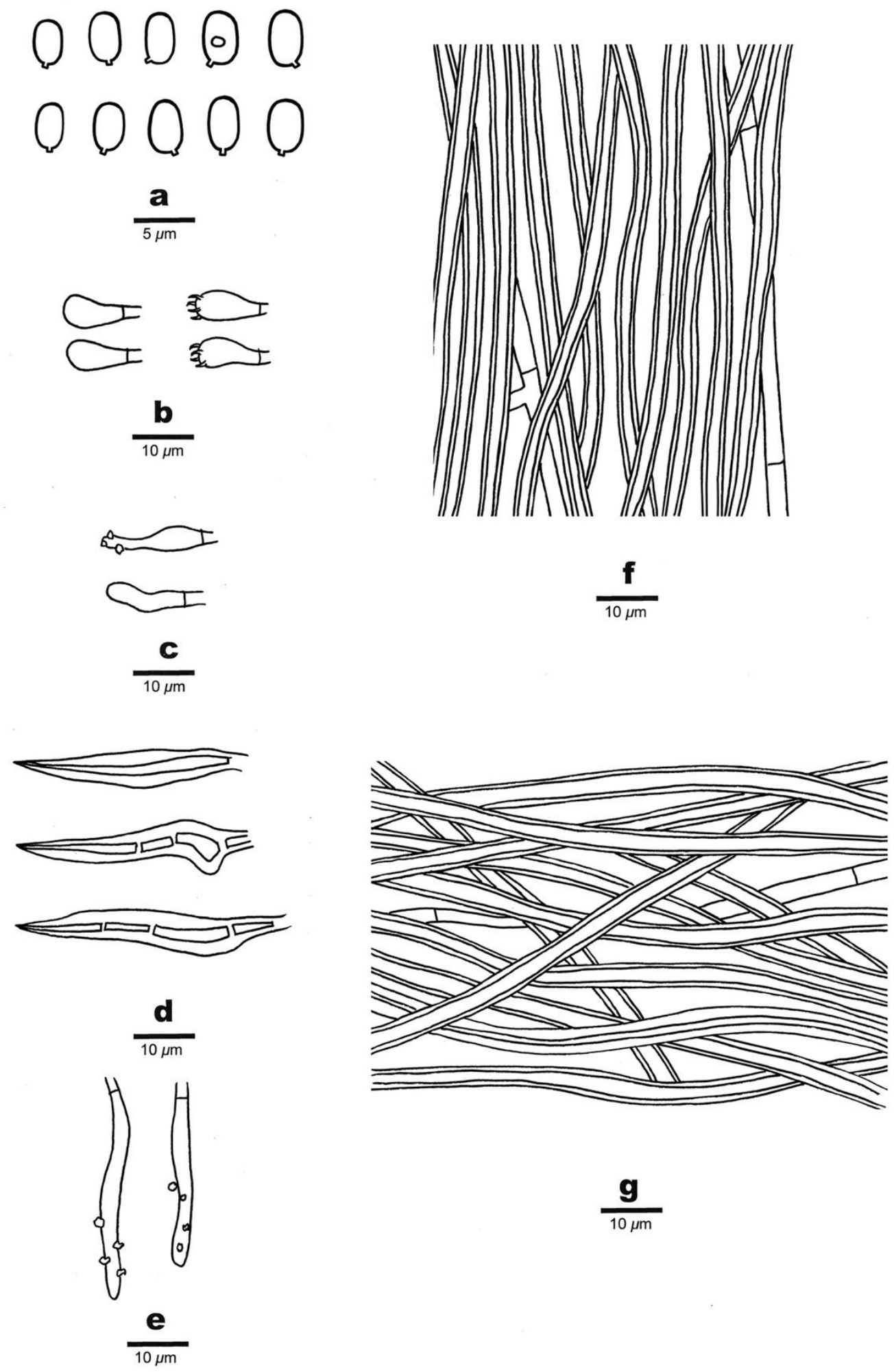

Figure 7 - Microscopic structures of Fuscoporia chinensis (holotype, Dai 15713). a Basidiospores. b Basidia and basidioles. c Cystidioles. d Hymenial setae. e Generative hyphae at dissepiment edge. f Hyphae from trama. g Hyphae from context.

Note - Fuscoporia chinensis is a common species in China. Morphologically, it is characterized by annual, effused-reflexed to pileate basidiocarps with indistinctly concentrically 
sulcate, velutinate to radially rugose pilear surface, small pores (7-8 per $\mathrm{mm}$ ), septate hymenial setae, and small, ellipsoid basidiospores measuring 3-4 × 2-2.5 $\mu \mathrm{m}$. Almost all specimens of $F$. chinensis were previously identified as F. gilva (Dai 1999, 2010, Chen \& Dai 2019, Chen et al. 2019), and now they are confirmed as different species and segregated from $F$. gilva, which has septate skeletal hyphae and larger basidiospores (4-5 × 3-3.5 $\mu \mathrm{m}$, Gilbertson 1979). Fuscoporia chinensis is closely related to $F$. plumeriae sp. nov. and $F$. formosana, but $F$. plumeriae has smaller pores (8-10 per $\mathrm{mm}$ ), aseptate hymenial setae, septate skeletal hyphae; $F$. formosana is distinguished from $F$. chinensis by larger pores (3-5 per mm, Chang \& Chou 1998).

Fuscoporia eucalypti Q. Chen, F. Wu \& Y.C. Dai, sp. nov.

MycoBank number: MB 833959; Facesoffungi number: FoF 07999.

Figs $3 g, 8$

Etymology - Eucalypti (Lat.): referring to the species growing on Eucalyptus.

Holotype - Australia, Tasmania, Arve River, Streamside Nature Reserve, on base of living Eucalyptus, 15 May 2018, Y.C. Dai 18792 (BJFC 027260, isotype in MEL).

Basidiocarps - Perennial, effused-reflexed to pileate, laterally fused, solitary to imbricate, without odor or taste and corky when fresh, light-weight and hard corky when dry. Pilei mostly dimidiate, projecting up to $5 \mathrm{~cm}$ long, $8 \mathrm{~cm}$ wide and $3 \mathrm{~cm}$ thick at the base. Pilear surface blackish brown to black, concentrically sulcate with zones, velutinate to glabrous; margin yellowish brown, distinctly paler than the pilear surface, obtuse. Pore surface grayish brown to fawn, more or less glancing, uncracked when dry, margin narrow, yellowish, up to $3 \mathrm{~mm}$ wide; pores more or less circular, 6-8 per $\mathrm{mm}$; dissepiments thin, entire, abundant hymenial setae in tube cavities (under anatomical lens). Context clay-buff, corky, about $2 \mathrm{~mm}$ thick. Tubes grayish brown to clay-buff, hard corky, up to $2.8 \mathrm{~cm}$ long, tube layers distinct.

Hyphal structure - Hyphal system dimitic; generative hyphae simple septate; tissue darkening but otherwise unchanged in $\mathrm{KOH}$.

Context - Generative hyphae rare, hyaline, thin- to slightly thick-walled, frequently branched and simple septate, 2-3 $\mu \mathrm{m}$ in diam.; skeletal hyphae dominant, rust-brown, thick-walled with a narrow lumen, unbranched, moderately septate, straight, regularly arranged, $2.5-3 \mu \mathrm{m}$ in diam.

Tubes - Generative hyphae rare, mostly present at dissepiment edges and subhymenium, hyaline, thin-walled, frequently branched and simple septate, 2-2.5 $\mu \mathrm{m}$ in diam, some of them encrusted at dissepiment edges and in hymenium; skeletal hyphae dominant, yellowish brown, thick-walled with a narrow lumen, septate, more or less straight, subparallel along the tubes, 2-3 $\mu \mathrm{m}$ in diam. Hymenial setae occasionally present, subulate, occasionally hooked, mostly originating from tramal hyphae, dark brown, thick-walled, $25-45 \times 5-8 \mu \mathrm{m}$; fusoid cystidioles hyaline and thin-walled, 18-28 $\times 3-6 \mu \mathrm{m}$; basidia short clavate to barrel-shaped, with four sterigmata and a simple septum at the base, usually bearing a medium size guttule, $14-18 \times 5.5-8 \mu \mathrm{m}$; basidioles dominating in hymenium, barrel-shaped, smaller than basidia.

Spores - Basidiospores subglobose, hyaline, thin-walled, smooth, usually bearing a small guttule, IKI-, CB-, (4-)4.3-5.5(-5.8) $\times(3.5-) 4-4.5(-4.6) \mu \mathrm{m}, \mathrm{L}=4.80 \mu \mathrm{m}, \mathrm{W}=4.16 \mu \mathrm{m}, \mathrm{Q}=$ $1.16-1.22(\mathrm{n}=90 / 3)$.

Other materials examined (paratypes) - Australia, Tasmania, Arve River, Streamside Nature Reserve, on stump of Eucalyptus, 15 May 2018, Y.C. Dai 18783 (BJFC 027251); on base of living Eucalyptus, 15 May 2018, Y.C. Dai 18791 (BJFC 027259), Y.C. Dai 18792 (BJFC 027260); Victoria, Yarra Ranges National Park, on base of living Eucalyptus, 10 May 2018, Y.C. Dai 18626A (BJFC 027095), Y.C. Dai 18634A (BJFC 027103); on dead tree of Eucalyptus, 10 May 2018, Y.C. Dai 18642A (BJFC 027111).

Note - Fuscoporia eucalypti grows on Eucalyptus sp. in South Australia. The species is characterized by fuscous to black brown pilear surface, occasionally hooked hymenial setae and subglobose basidiospores, $4.3-5.5 \times 4-4.5 \mu \mathrm{m}$. F . eucalypti is similar to $F$. atlantica by effusedreflexed to pileate basidiocarps, small pores $(7-9$ per $\mathrm{mm}$ ) and hooked hymenial setae, but $F$. atlantica has ellipsoid basidiospores $(4-4.5 \times 3-3.5 \mu \mathrm{m}, \mathrm{Q}=1.5$, Pires et al. 2015), and the two species are not closely related phylogenetically (Figs 1-2). Fuscoporia eucalypti is closely related 
phylogenetically to $F$. wahlbergii and $F$. australasica (Figs 1-2). However, the latter two species have narrower basidiospores (3.3-4 $\mu \mathrm{m}$ and 3.3-4.2 $\mu \mathrm{m}$, respectively, Dai 2010). In addition, a comparison of nucleotide differences in ITS region shows that $F$. eucalypti differs respectively from $F$. australasica and $F$. wahlbergii by 2.5 and $2 \%$, and at least $1.5 \%$ nucleotide differences in the ITS regions was proposed as indicative of a new species (Jeewon \& Hyde 2016).
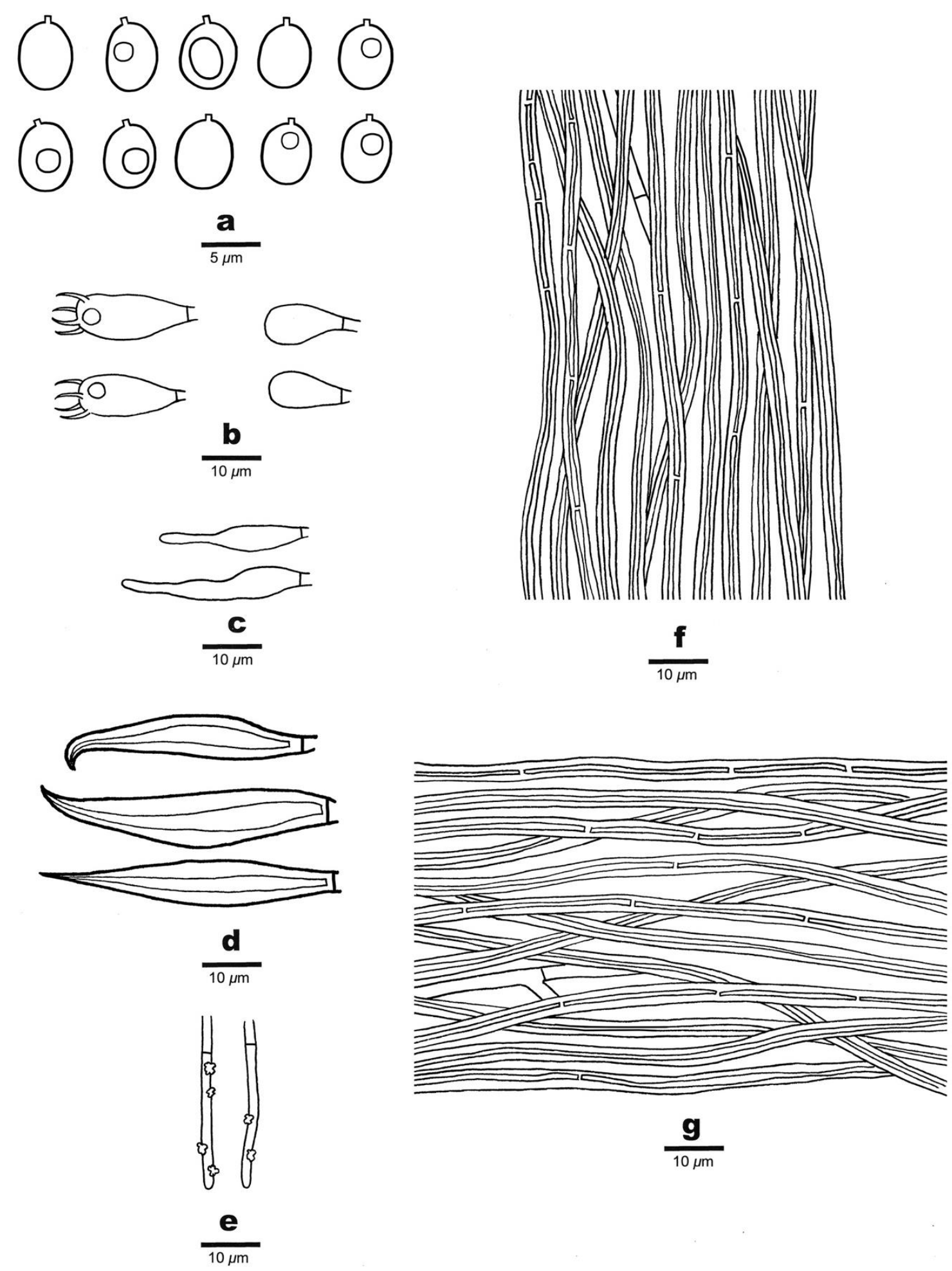
Figure 8 - Microscopic structures of Fuscoporia eucalypti (holotype, Dai 18792). a Basidiospores. b Basidia and basidioles. c Cystidioles. d Hymenial setae. e Generative hyphae at dissepiment edge. f Hyphae from trama. g Hyphae from context.

Fuscoporia karsteniana Q. Chen, F. Wu \& Y.C. Dai, sp. nov.

Figs $3 h, 9$

MycoBank number: MB 833962; Facesoffungi number: FoF 08000.

Etymology - Karsteniana (Lat.): in honor of the Finnish mycologist Petter Adolf Karsten.

Holotype - China, Jilin Province, Antu County, Changbaishan Nature Reserve, on Populus, 9 Oct 2009, Y.C. Dai 11403 (BJFC 007308).

Basidiocarps - Perennial, resupinate, inseparable, without odor or taste and soft corky when fresh, corky and light-weight when dry, up to $16 \mathrm{~cm}$ long, $5 \mathrm{~cm}$ wide and $7 \mathrm{~mm}$ thick at centre. Pore surface rusty brown, more or less fawn, occasionally cracked when dry, sterile margin narrow or almost lacking, up to $1 \mathrm{~mm}$ wide, honey-yellow, distinctly paler than pore surface, usually with mycelial setae; pores more or less circular, 5-7 per $\mathrm{mm}$; dissepiments thin, entire, abundant hymenial setae seen in tube cavities (under anatomical lens). Subiculum cinnamon to reddish brown, corky, very thin, less $0.3 \mathrm{~mm}$ thick. Tubes grayish brown, paler contrasting with subiculum, hard corky, up to $6.7 \mathrm{~mm}$ long.

Hyphal structure - Hyphal system dimitic; generative hyphae simple septate; tissue darkening but otherwise unchanged in $\mathrm{KOH}$.

Subiculum - Generative hyphae rare, hyaline, thin-walled, occasionally branched, frequently simple septate, 2-2.5 $\mu \mathrm{m}$ in diam.; skeletal hyphae dominant, rust-brown, thick-walled with a narrow to medium lumen, unbranched, aseptate, more or less straight, interwoven, 2.5-3 $\mu \mathrm{m}$ in diam.; mycelial setae frequent, dark reddish brown, thick-walled, tapering to apex, occasionally septate, present in the subiculum, sometimes locally abundant, often in bundles, up to $265 \mu \mathrm{m}$ long and 5-9 $\mu \mathrm{m}$ in the widest part.

Tubes - Generative hyphae rare, mostly present at dissepiment edges and subhymenium, hyaline, thin-walled, frequently branched and simple septate, 1.5-2.2 $\mu \mathrm{m}$ in diam., some of them encrusted at dissepiment edges and in hymenium; skeletal hyphae dominant, yellowish brown, thick-walled with a narrow to medium lumen, unbranched, aseptate, more or less straight, subparallel along the tubes, 2.3-2.8 $\mu \mathrm{m}$ in diam. Hymenial setae frequent, narrowly subulate, mostly originating from tramal hyphae, dark brown, thick-walled, 34-45 $\times 5-7.5 \mu \mathrm{m}$; basidia barrel-shaped, with four sterigmata and a simple septum at the base, occasionally bearing a small guttule, 14-16 $\times 4-6 \mu \mathrm{m}$; basidioles dominating in hymenium, in shape similar to basidia, but slightly smaller.

Spores - Basidiospores ellipsoid, hyaline, thin-walled, smooth, usually glued in tetrads, bearing a small guttule, IKI-, CB-, 4.5-5.6(-5.8) $\times(2.8-) 3-3.8(-3.9) \mu \mathrm{m}, \mathrm{L}=5.05 \mu \mathrm{m}, \mathrm{W}=3.37$ $\mu \mathrm{m}, \mathrm{Q}=1.50-1.65(\mathrm{n}=60 / 2)$.

Other materials examined (paratypes) - China, Guizhou Province, Libo County, Maolan Nature Reserve, on fallen trunk of Prunus, 15 Jun 2016, Y.C. Dai 16552 (BJFC 022664); Hubei Province, Yichang, Wufeng County, Chaibuxi Park, on dead angiosperm tree, 15 Aug 2017, Y.C. Dai 17925 (BJFC 025454); Shennongjia Park, on fallen angiosperm trunk, 16 Oct 2016, Y.C. Dai 17229 (BJFC 023327); Yunnan Province, Binchuan County, Jizushan Nature Reserve, on fallen trunk of Quercus, 30 Aug 2015, Y.C. Dai 15717 (BJFC 019821); Yuxi, Xinping County, Mopanshan Forest Park, on dead tree of Schima, 15 Jun 2017, Y.C. Dai 17618 (BJFC 025150); on dead angiosperm tree, 15 Jun 2017, Y.C. Dai 17629 (BJFC 025161).

Note - Fuscoporia karsteniana is widely distributed in China and characterized by perennial basidiocarps, septate mycelial setae, absence of cystidioles, and ellipsoid basidiospores measuring 4.5-5.6 $\times 3-3.8 \mu \mathrm{m}$. The new species is closely related to $F$. ferruginosa sensu stricto in our phylogenies (Figs 1-2), but $F$. ferruginosa sensu stricto has mostly annual and nodulose basidiocarps, very thick dissepiments (> pore diam.), presence of cystidioles, aseptate mycelial setae; while $F$. karsteniana has perennial, resupinate and even basidiocarps, thin dissepiments $(<$ pore diam.), absence of cystidioles, some septate mycelial setae. Fuscoporia chinensis is another common species in China, it differs from $F$. karsteniana by effused-reflexed to pileate basidiocarps 
and absence of mycelial setae.

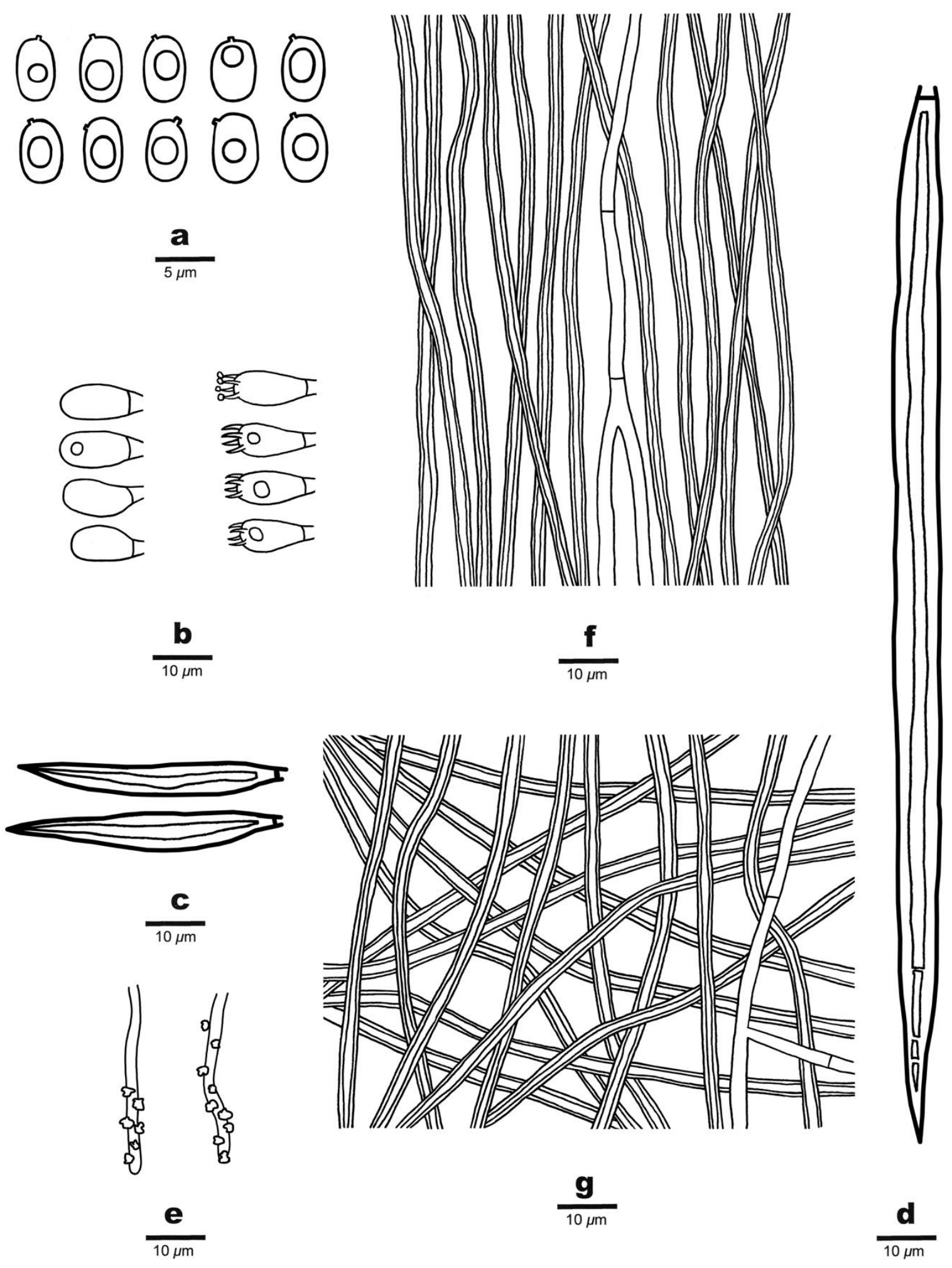

Figure 9 - Microscopic structures of Fuscoporia karsteniana (holotype, Dai 11403). a Basidiospores. b Basidia and basidioles. c Hymenial setae. d Mycelial setae. e Generative hyphae at dissepiment edge. $\mathrm{f}$ Hyphae from trama. $g$ Hyphae from subiculum.

Fuscoporia plumeriae Q. Chen, F. Wu \& Y.C. Dai, sp. nov.

Figs 10a, b, 11

MycoBank number: MB 833957; Facesoffungi number: FoF 08001.

Etymology - Plumeriae (Lat.): referring to the species growing on Plumeria. 
Holotype - Australia, Queensland, Cains, Crater Lake National Park, on dead tree of Plumeria, 18 May 2018, Y.C. Dai 18858 (BJFC 027326, isotype in MEL).

Basidiocarps - Annual, pileate, solitary, corky and without taste or odor when fresh, becoming hard corky and light-weight when dry. Pilei mostly dimidiate to conchate, projecting up to $7 \mathrm{~cm}$ long, $13 \mathrm{~cm}$ wide and $3.5 \mathrm{~cm}$ thick at the base. Pilear surface grayish brown to olivaceous buff, indistinctly concentrically zonate, nodulose; margin obtuse, honey-yellow. Pore surface fuscous, slightly glancing; margin narrow, honey-yellow, paler than pore surface, up to $1 \mathrm{~mm}$; pores circular, 8-10 per $\mathrm{mm}$; dissepiments thin, entire to slightly lacerate; abundant setae seen in tube cavities (under anatomical lens). Context honey-yellow, corky, zonate, up to $3 \mathrm{~cm}$ thick. Tubes grayish brown, paler than pore surface, hard corky up to $0.5 \mathrm{~cm}$ long.

Hyphal structure - Hyphal system dimitic; generative hyphae simple septate; tissue darkening but otherwise unchanged in $\mathrm{KOH}$.

Context - Generative hyphae frequent, hyaline, thin- to slightly thick-walled, occasionally branched, frequently simple septate, $2-3 \mu \mathrm{m}$ in diam.; skeletal hyphae dominant, yellowish brown, thick-walled with a wide lumen, unbranched, occasionally septate, straight, regularly arranged, 3-5 $\mu \mathrm{m}$ in diam.

Tubes - Generative hyphae frequent, mostly present at dissepiment edges and subhymenium, hyaline, thin-walled, frequently branched and septate, 2-3 $\mu \mathrm{m}$ in diam, some of them encrusted at dissepiment edges and in hymenium; skeletal hyphae dominant, yellowish brown, thick-walled with a wide lumen, unbranched, occasionally septate, straight, parallel along the tubes, $3-4 \mu \mathrm{m}$ in diam. Hymenial setae frequent, mostly originating from tramal hyphae, ventricose to subulate, dark brown, thick-walled, 15-25 $\times 5-6 \mu \mathrm{m}$; fusoid cystidioles hyaline, thin-walled, sometimes covered by crystals, $12-18 \times 2-3 \mu \mathrm{m}$; basidia short clavate to barrel-shaped, with four sterigmata and a simple septum at the base, $12-17 \times 5-6.5 \mu \mathrm{m}$; basidioles dominating in hymenium, barrel-shaped to capitate, smaller than basidia.

Spores - Basidiospores ellipsoid, hyaline, thin-walled, smooth, IKI-, CB-, 3-3.8(-4) $\times(2-$ )2.2-2.8(-3) $\mu \mathrm{m}, \mathrm{L}=3.54 \mu \mathrm{m}, \mathrm{W}=2.54 \mu \mathrm{m}, \mathrm{Q}=1.31-1.40(\mathrm{n}=60 / 2)$.

Other materials examined (paratypes) - Australia, Queensland, Cains, Crater Lake National Park, on fallen trunk of Plumeria, 17 May 2018, Y.C. Dai 18820 (BJFC 027288); Mt. Whitfield Coservation Park, on dead tree of Plumeria, 18 May 2018, Y.C. Dai 18861 (BJFC 027329). Singapore, Bukit Timah Nature Reserve, on fallen angiosperm trunk, 18 Jul 2017, Y.C. Dai 17814 (BJFC 025346).

Note - Fuscoporia plumeriae is characterized by annual and pileate basidiocarps with nodulose pilear surface, small pores $(8-10$ per $\mathrm{mm})$, short hymenial setae $(<25 \mu \mathrm{m}$ long), septate skeletal hyphae, small and ellipsoid basidiospores measuring 3-3.8 $\times 2.2-2.8 \mu \mathrm{m}$, and distributed in northern Australia and Singapore. It is a unique species in the genus that its context is thicker than the tubes. Macromorphologically $F$. plumeria resembles $F$. gilva and $F$. australiana, but $F$. gilva has larger pores $(6-8$ per $\mathrm{mm})$ and larger basidiospores $(4-5 \times 3-3.5 \mu \mathrm{m}$, Gilbertson 1979, Ryvarden \& Johansen 1980). On the other hand, F. australiana has acute margin, aseptate skeletal hyphae and longer basidiospores $(4-4.8 \mu \mathrm{m})$.

Fuscoporia shoreae Q. Chen, F. Wu \& Y.C. Dai, sp. nov.

Figs 10c, d, 12

MycoBank number: MB 833969; Facesoffungi number: FoF 08002.

Etymology - Shoreae (Lat.): referring to the species growing on Shorea sp.

Holotype - Singapore, Bukit Timah Nature Reserve, on living tree of Shorea, 18 Jul 2017, Y.C. Dai 17818 (BJFC 025350).

Basidiocarps - Annual, pileate, solitary, corky and without odor or taste when fresh, hard corky when dry. Pilei mostly dimidiate, projecting up to $6 \mathrm{~cm}$ long, $9 \mathrm{~cm}$ wide and $1 \mathrm{~cm}$ thick at the base. Pilear surface grayish brown, concentrically sulcate with zones; margin obtuse, yellowish brown, distinctly paler than pilear surface. Pore surface curry-yellow to olivaceous buff, sterile margin distinct, yellowish, up to $3 \mathrm{~mm}$ wide; pores circular, 9-10 per $\mathrm{mm}$; dissepiments thick, entire. Context curry-yellow, corky, about $0.8 \mathrm{~cm}$ thick. Tubes olivaceous buff, hard corky, up to 


\section{$0.2 \mathrm{~cm}$ long.}

Hyphal structure - Hyphal system dimitic; generative hyphae simple septate; tissue darkening but otherwise unchanged in $\mathrm{KOH}$.

Context - Generative hyphae rare, hyaline, thin-walled, frequently branched and simple septate, 1.5-2 $\mu \mathrm{m}$ in diam.; skeletal hyphae dominant, rust-brown, thick-walled with a narrow lumen, unbranched, frequently septate, flexuous, interwoven, $2.5-3 \mu \mathrm{m}$ in diam.

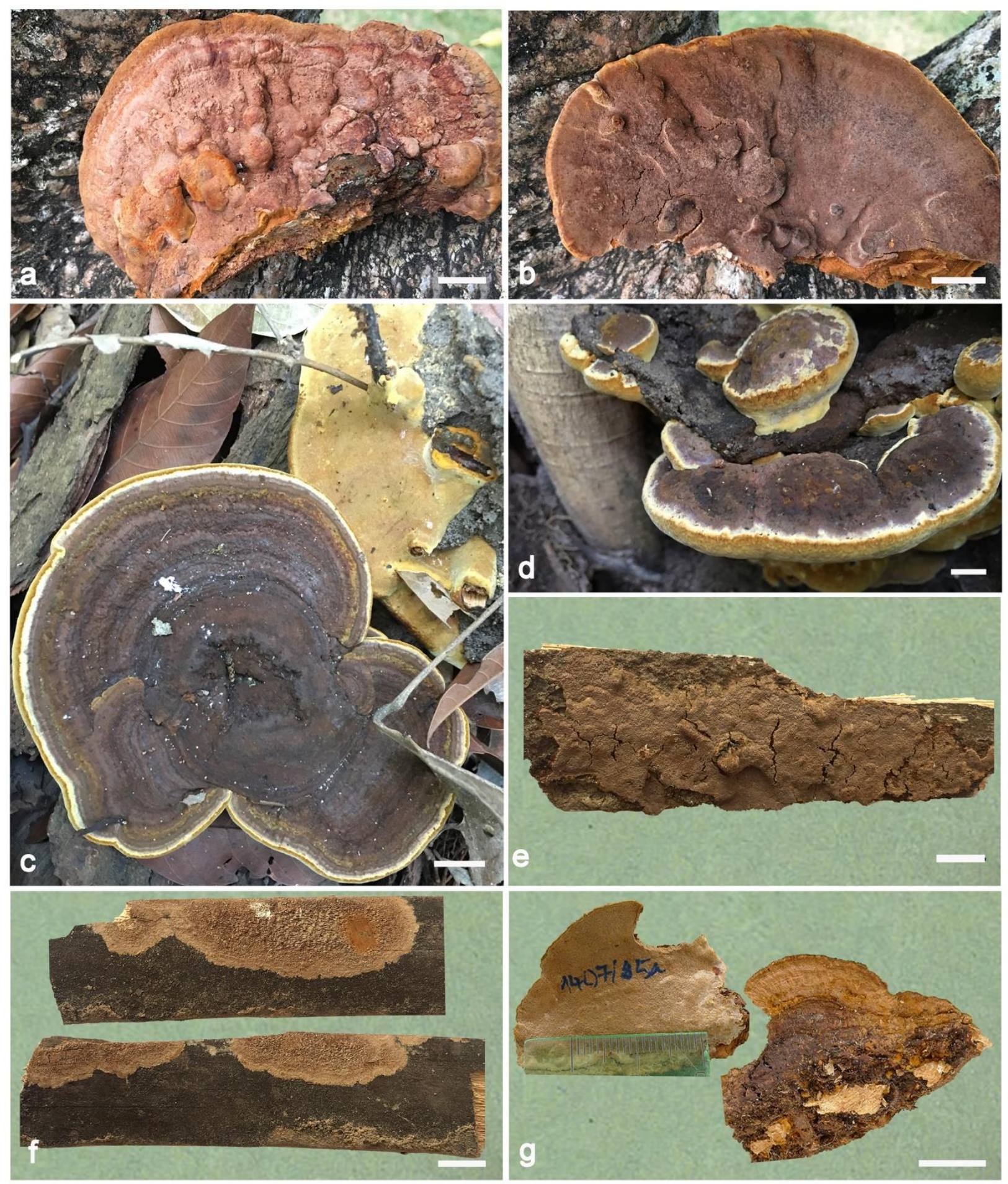

Figure 10 - Basidiocarps of Fuscoporia species. a-b Fuscoporia plumeriae (holotype, Dai 18858). c-d Fuscoporia shoreae (c holotype, Dai 17818, d paratype, Dai 17800). e Fuscoporia subchrysea (holotype, Dai 16201). f Fuscoporia bambusicola (holotype, Cui 8692). g Fuscoporia roseocinerea (holotype, JV 1407/85). Scale Bars $=10 \mathrm{~mm}$. 


\section{OODQD \\ 00000 \\ $\frac{\mathbf{a}}{5 \mu \mathrm{m}}$}
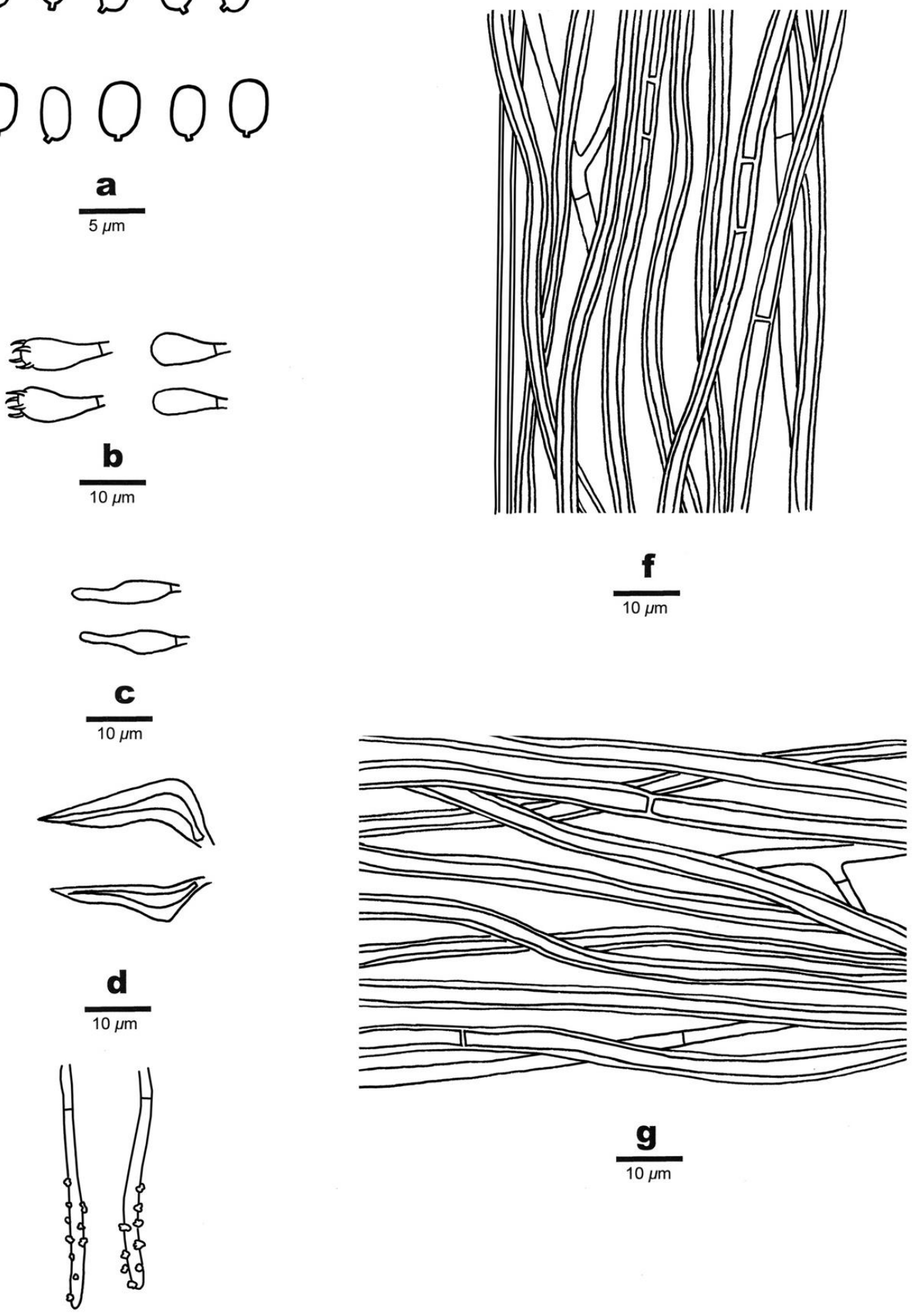

$$
\frac{\mathbf{e}}{10 \mu \mathrm{m}}
$$

Figure 11 - Microscopic structures of Fuscoporia plumeriae (holotype, Dai 18858). a Basidiospores. b Basidia and basidioles. c Cystidioles. d Hymenial setae. e Generative hyphae at dissepiment edge. f Hyphae from trama. g Hyphae from context.

Tubes - Generative hyphae frequent, mostly present at dissepiment edges and subhymenium, hyaline, thin-walled, frequently branched and simple septate, $1.5-2 \mu \mathrm{m}$ in diam.; skeletal hyphae dominant, yellowish brown, thick-walled with a narrow lumen, frequently septate, more or less straight, subparallel along the tubes, 2-2.5 $\mu \mathrm{m}$ in diam. Hymenial setae absent; fusoid cystidioles 
hyaline and thin-walled, $16-22 \times 3.5-5.5 \mu \mathrm{m}$; basidia barrel-shaped to capitate, with four sterigmata and a simple septum at the base, 12-15 × 4.5-6 $\mu \mathrm{m}$; basidioles dominating in hymenium, in shape similar to basidia, almost the same size of basidia.
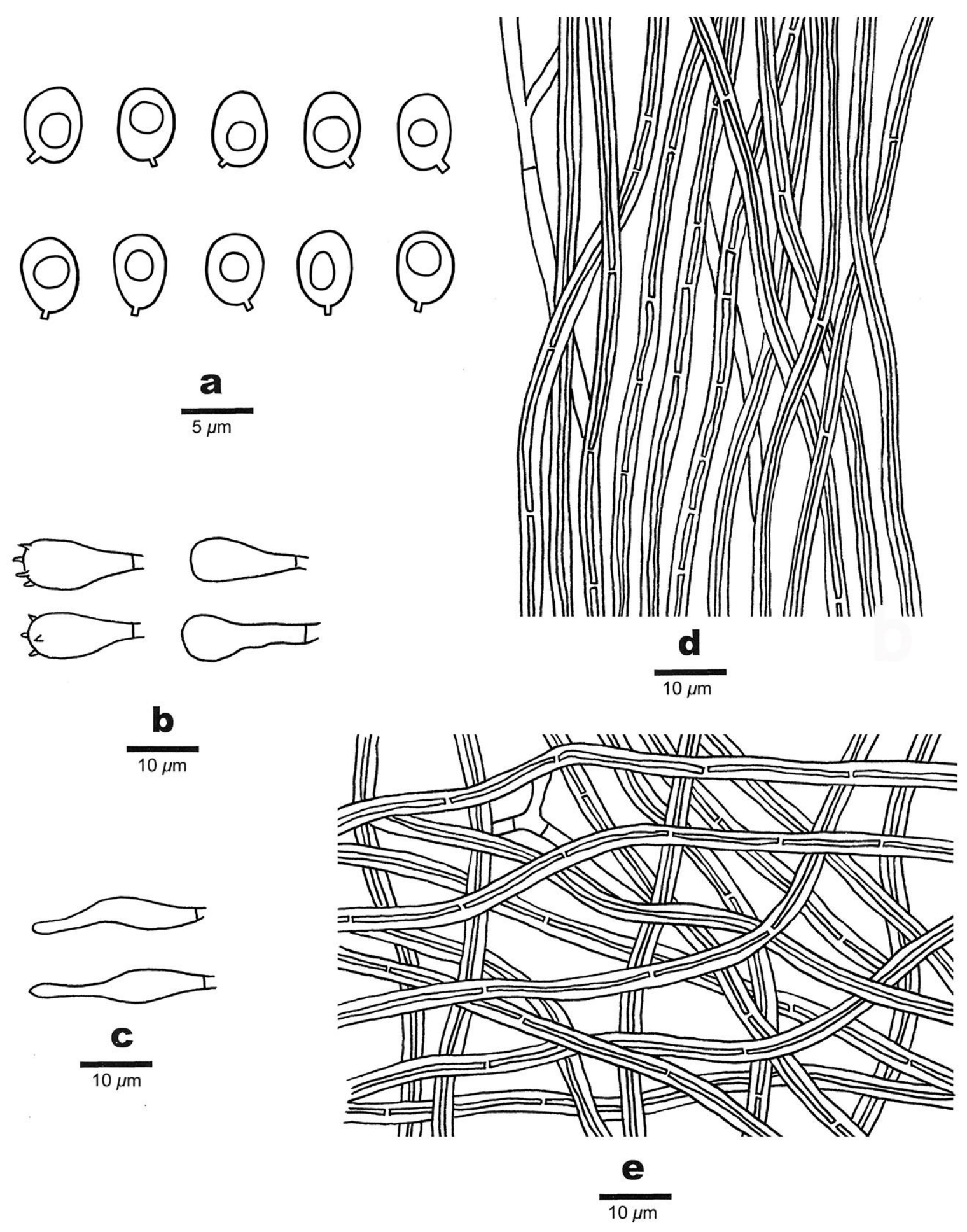

Figure 12 - Microscopic structures of Fuscoporia shoreae (holotype, Dai 17818). a. Basidiospores. b. Basidia and basidioles. c. Cystidioles. d. Hyphae from trama. e. Hyphae from context.

Spores - Basidiospores broadly ellipsoid, hyaline, thin-walled, smooth, bearing a medium guttule, IKI-, CB-, (3.5-)3.8-4.8(-5) $\times(2.6-) 3-3.8(-4) \mu \mathrm{m}, \mathrm{L}=4.18 \mu \mathrm{m}, \mathrm{W}=3.34 \mu \mathrm{m}, \mathrm{Q}=1.24-$ $1.30(n=60 / 2)$. 
Other materials examined (paratypes) - Singapore, Bukit Timah Nature Reserve, on fallen angiosperm trunk, 18 Jul 2017, Y.C. Dai 17800 (BJFC 025332), Y.C. Dai 17806 (BJFC 025338).

Note - Three specimens of Fuscoporia shoreae from Singapore are clustered into a lineage with high support (100/100 in Fig. 2). The species is phylogenetically nested in Fuscoporia, although morphologically it doesn't present hymenial setae and encrustations on generative hyphae. In fact, $F$. longisetulosa (Bondartseva \& S. Herrera) Bondartseva \& S. Herrera and $F$. discipes (Berk.) Y.C. Dai \& Ghob.-Nejh. neither present hymenial setae, F. discipes differs from $F$. shoreae by its larger pores (6-8 per mm, Ryvarden \& Johansen 1980, Dai 2010) and usually laterally stipitate; F. longisetulosa differs from $F$. shoreae by presence of mycelial setae (Ryvarden 2004). It seems that the hymenial setae are not an important character for diagnosis of Fuscoporia although most species in the genus have hymenial setae, and the hyaline, thin-walled basidiospores are the basic character for definition of the genus.

Fuscoporia subchrysea Q. Chen, F. Wu \& Y.C. Dai, sp. nov.

Figs $10 \mathrm{e}, 13$

MycoBank number: MB 833961; Facesoffungi number: FoF 07992.

Etymology - Subchrysea (Lat.): referring to the species similar to Fuscoporia chrysea.

Holotype - China, Hainan Province, Wuzhishan County, Wuzhishan Nature Reserve, on dead bamboo, 15 Nov 2015, Y.C. Dai 16201 (BJFC 020287).

Basidiocarps - Annual, resupinate, inseparable, soft corky and without odor or taste when fresh, becoming corky and light-weight upon drying, up to $18 \mathrm{~cm}$ long, $4 \mathrm{~cm}$ wide and $1 \mathrm{~mm}$ thick at centre. Pore surface fuscous to honey-yellow or fawn, occasionally cracked when dry; sterile margin cinnamon-buff, distinctly paler than pore surface, usually with abundant mycelial setae, up to $1 \mathrm{~mm}$ wide; pores more or less circular, 8-9 per $\mathrm{mm}$; dissepiments thin, entire, abundant hymenial setae seen in tube cavities (under anatomical lens). Subiculum reddish brown, corky, very thin, up to $0.2 \mathrm{~mm}$ thick. Tubes grayish brown, paler than subiculum, hard corky, up to $0.8 \mathrm{~mm}$ long.

Hyphal structure - Hyphal system dimitic; generative hyphae simple septate; tissue darkening but otherwise unchanged in $\mathrm{KOH}$.

Subiculum - Generative hyphae rare, hyaline, thin-walled, occasionally branched, frequently simple septate, 2-3.5 $\mu \mathrm{m}$ in diam.; skeletal hyphae dominant, rust-brown, thick-walled with a wide lumen, unbranched, occasionally septate, flexuous, interwoven, 3.5-4 $\mu \mathrm{m}$ in diam.; mycelial setae frequent, dark reddish brown, thick-walled, tapering to apex, present in the subiculum and in the rotten wood cavities, sometimes locally abundant, often in bundles, up to $130 \mu \mathrm{m}$ long and 6-9 $\mu \mathrm{m}$ in the widest part.

Tubes - Generative hyphae frequent, mostly present at dissepiment edges and subhymenium, hyaline, thin-walled, occasionally branched and frequently simple septate, 1.5-3 $\mu \mathrm{m}$ in diam, some of them encrusted at dissepiment edges and in hymenium; skeletal hyphae dominant, yellowish brown, thick-walled with a medium or wide lumen, unbranched, aseptate, more or less straight, subparallel along the tubes, 3-4 $\mu \mathrm{m}$ in diam. Hymenial setae frequent, narrowly subulate, mostly originating from tramal hyphae, dark brown, thick-walled, 40-68 $\times 5-8 \mu \mathrm{m}$; basidia barrel-shaped, with four sterigmata and a simple septum at the base, 11-13 $\times 5-7.5 \mu \mathrm{m}$; basidioles dominating in hymenium, capitate, but shorter than basidia.

Spores - Basidiospores ellipsoid, hyaline, thin-walled, smooth, usually glued in tetrads, sometimes bearing a small guttule, IKI-, CB-, 3.8-4.4(-4.7) $\times 2.6-3.2(-3.4) \mu \mathrm{m}, \mathrm{L}=4.07 \mu \mathrm{m}, \mathrm{W}=$ $3 \mu \mathrm{m}, \mathrm{Q}=1.31-1.42(\mathrm{n}=60 / 2)$.

Other material examined (paratype) - China, Hainan Province, Baoting County, Qixianling Forest Park, on fallen angiosperm trunk, 8 Jun 2017, Y.C. Dai 17656 (BJFC 025188).

Note - Fuscoporia subchrysea is characterized by small pores (8-9 per $\mathrm{mm})$, septate skeletal hyphae, long hymenial setae $(>40 \mu \mathrm{m})$, presence of mycelial setae and absence of cystidioles. The species may be confused with $F$. chrysea (Lév.) Baltazar \& Gibertoni by the similar resupinate basidiocarps, small pores (9-10 per $\mathrm{mm}$ in $F$. chrysea) and broadly ellipsoid basidiospores. However, $F$. chrysea has perennial basidiocarps with bright golden yellow pore surface and absence 
of mycelial setae (Ryvarden \& Johansen 1980, Ryvarden 2004, Dai 2010). In addition, $F$. subchrysea and $F$. chrysea are genetically very distant species (Fig. 2). Fuscoporia bambusae and $F$. subchrysea are found in tropical Asia, and both species can grow on bamboo. However, pores are bigger in $F$. bambusae than in $F$. subchrysea (5-7 per $\mathrm{mm}$ vs. 8-9 per $\mathrm{mm}$ ), and spores are longer in $F$. bambusae than in F. subchrysea $(4.3-5.3 \mu \mathrm{m}$ vs. 3.8-4.4 $\mu \mathrm{m})$.

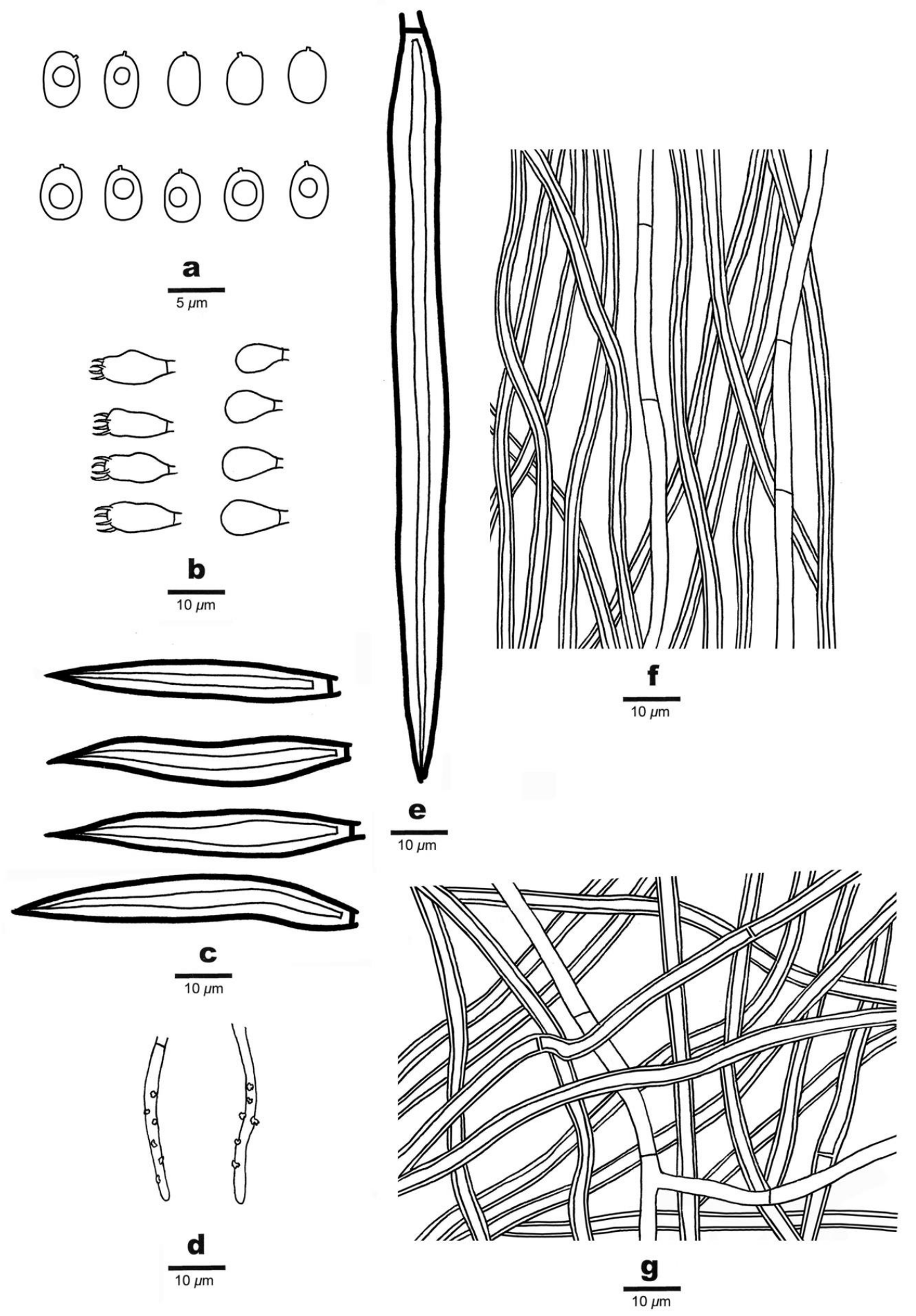

Figure 13 - Microscopic structures of Fuscoporia subchrysea (holotype, Dai 16201). a Basidiospores. b Basidia and basidioles. c Hymenial setae. d Generative hyphae at dissepiment edge. e Mycelial setae. f Hyphae from trama. g Hyphae from subiculum. 
Fuscoporia bambusicola (L.W. Zhou \& B.S. Jia) Q. Chen, F. Wu \& Y.C. Dai, comb. nov.

Figs 10f, 14

MycoBank number: MB 833968; Facesoffungi number: FoF 07993.

Basionym: Phellinus bambusicola L.W. Zhou \& B.S. Jia, Mycotaxon 114: 212 (2010).

Material examined - China, Hainan Province, Changjiang County, Bawangling Nature Resever, on dead bamboo, 8 Jul 2009, B.K. Cui 8692 (BJFC 007632, holotype).

Note - Fuscoporia bambusicola was originally described as Phellius bambusicola from southern China based on morphology (Zhou \& Jia 2010). Its holotype was studied and DNA was extracted. Our phylogenetic analysis indicated that $F$. bambusicola nested in Fuscoporia. It is therefore the above combinaton is proposed. Fuscoporia bambusicola is closely related to $F$. latispora Y.C. Dai, Q. Chen \& J. Vlasák (Figs 1-2), but F. latispora has mycelial setae often in sterile margin which lead the sterile margin darker than pores surface, longer hymenial setae (55-72 $\mu \mathrm{m}$ ), and a distribution in Central America (Chen et al. 2019); while F. bambusicola has mycelial setae in subiculum rather than at sterile margin, shorter hymenial setae $(32-54 \mu \mathrm{m})$, and occurs in tropical China (Zhou \& Jia 2010). Fuscoporia monticola also occurs in southern China, it resembles $F$. bambusicola by similar basidiocarps and presence of mycelial setae, but it has larger pores (2-3 per $\mathrm{mm}$ vs. 3-5 per $\mathrm{mm}$ in $F$. bambusicola) and oblong ellipsoid basidiospores (4.4-6.3 × 2.4-3.2 $\mu \mathrm{m}$ vs. $4.2-5 \times 3.1-4 \mu \mathrm{m}$ in F. bambusicola, Chen et al. 2019, Zhou \& Jia 2010). Fuscoporia bambusae grows also on bamboo, but it differs from $F$. bambusicola by smaller pores (5-7 per $\mathrm{mm}$, 3-5 per $\mathrm{mm}$ in $F$. bambusicola), In addition, both species are phylogenetically distant (Figs 1-2).

Fuscoporia roseocinerea (Murrill) Q. Chen, F. Wu \& Y.C. Dai, comb. nov.

Figs $10 \mathrm{~g}, 15$

MycoBank number: MB 833970; Facesoffungi number: FoF 07994.

Basionym: Pyropolyporus roseocinereus Murrill, N. Amer. Fl. (New York) 9: 104 (1908).

$\equiv$ Phellinus roseocinereus (Murrill) D.A. Reid, Mem. N. Y. bot. Gdn 28: 194 (1976).

Materials examined - Costa Rica, Guanacaste Province, Lomas de Barbudal Biological Reserve, on hardwood, Jul 2014, J. Vlasák, JV 1407/84 (duplicate in BJFC 020687), JV 1407/85 (duplicate in BJFC 020686); Parque Nacional Santa Rosa, on hardwood, Aug 2014, J. Vlasák, JV 1408/31 (duplicate in BJFC 020688). USA, Texas, Brownswille, Resaca de la Palma State Park, on Acacia farnesiana, Sep 2011, J. Vlasák, JV 1109/78-J (duplicate in BJFC 020653).

Note - Fuscoporia roseocinerea was originally described as Pyropolyporus roseocinereus from Costa Rica and Cuba (Murrill 1908) and combined as Phellinus roseocinereus for a long time (Reid 1976). Three specimens from USA and Costa Rica were studied, which presented a dimitic hyphal system with encrustations on generative hyphae and broadly ellipsoid, hyaline, thin-walled basidiospores $(4-5 \times 3-3.6 \mu \mathrm{m}, \mathrm{Q}=1.30-1.35)$. These data are more or less close to the descriptions by Murrill (1908) and Reid (1976). In addition, these three samples nested in Fuscoporia and clustered into a lineage with high support (100/100 in Fig. 2), so Fuscoporia roseocinerea is proposed.

Following Murrill (1908), Fuscoporia roseocinerea is characterized by perennial, effusedreflexed basidiocarps, encrusted pilear surface with concentrically sulcate, acute margin, round pores, 5-6 per mm, entire dissepiments, globose to ovoid, smooth, hyaline basidiospores, 5-6 × 3-4 $\mu \mathrm{m}$. However, Lowe (1957) mentioned the species has pores as 6-10 per $\mathrm{mm}$, and spores as broadly oval, 3.5-4 × 2-3 $\mu \mathrm{m}$ (Larsen \& Cobb-Poulle 1990). So, there are very different morphologies on this species. We did not study its type, and further study in needed to confirm its morphology.

Fuscoporia roseocinerea is similar to F. callimorpha (Lév.) Groposo, Log.-Leite \& GóesNeto but the latter has smaller pores (7-10 per $\mathrm{mm})$ and oblong ellipsoid basidiospores $(3.5-4.5 \times$ 2-3 $\mu \mathrm{m}$, Lowe 1957, Ryvarden \& Johansen 1980, Raymundo et al. 2013a). Fuscoporia chrysea (type locality in Colombia) is closely related to $F$. roseocinerea (Figs 1-2), but the former species has smaller basidiospores (3-4 × 2-2.5 $\mu \mathrm{m}$, Ryvarden 2004). 

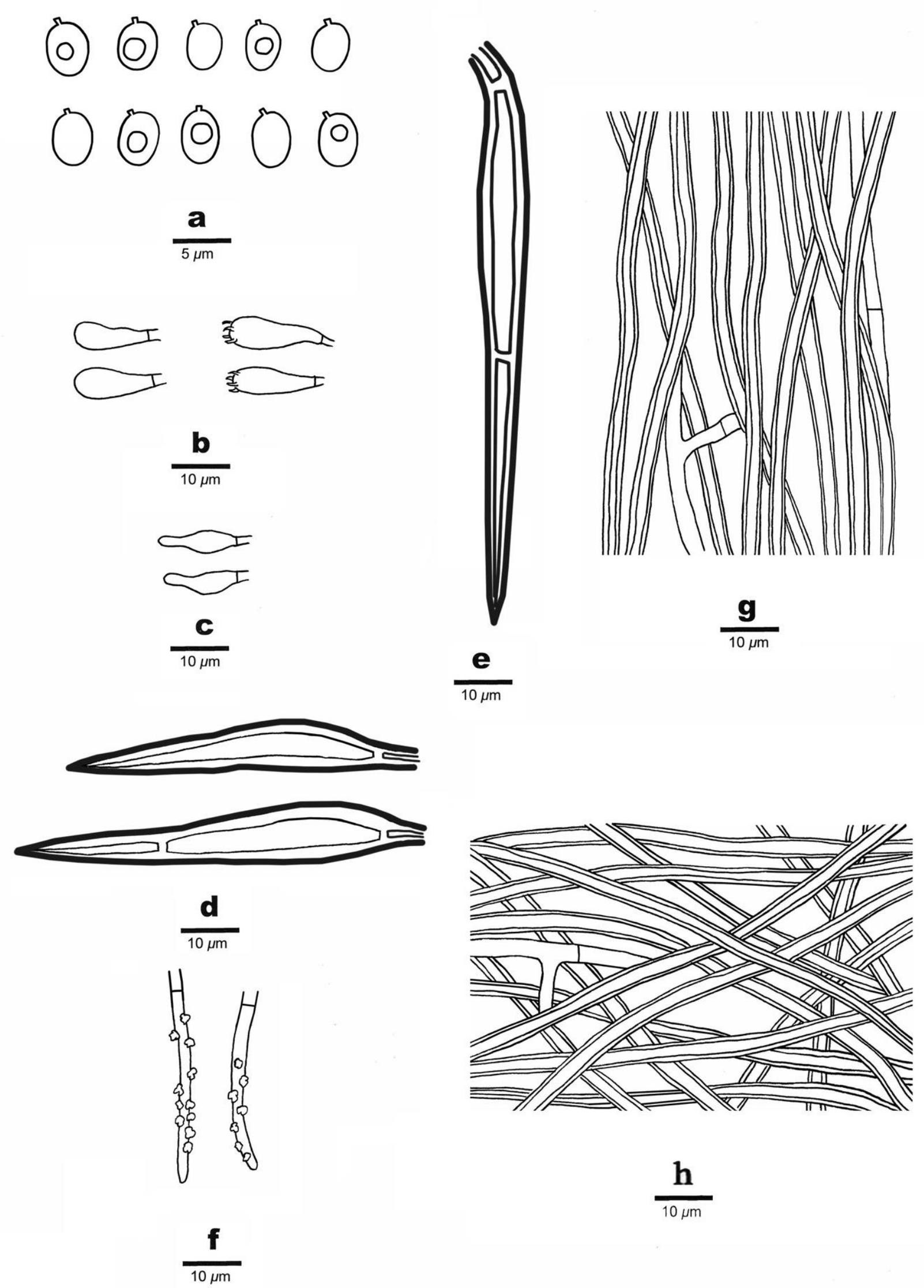

Figure 14 - Microscopic structures of Fuscoporia bambusicola (holotype, Cui 8692). a Basidiospores. b Basidia and basidioles. c Cystidioles. d Hymenial setae. e Mycelial setae. f Generative hyphae at dissepiment edge. g Hyphae from trama. h Hyphae from subiculum. 

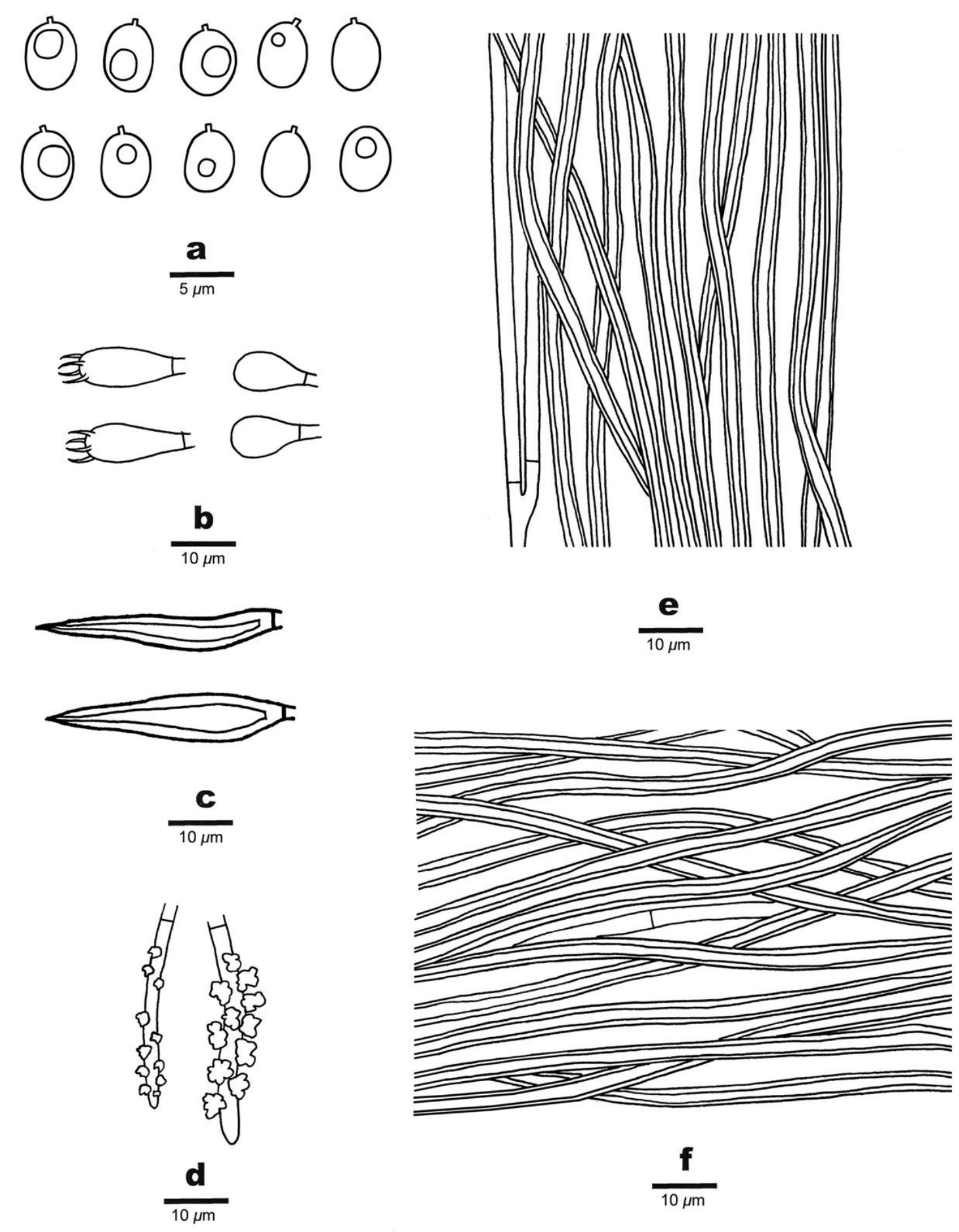

Figure 15 - Microscopic structures of Fuscoporia roseocinerea (JV 1407/84), a Basidiospores. b Basidia and basidioles. c Hymenial setae. d Generative hyphae at dissepiment edge. e Hyphae from trama. f Hyphae from context.

\section{A key to species of Fuscoporia in worldwide}

1. Basidiocarps resupinate

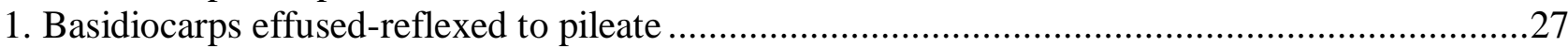

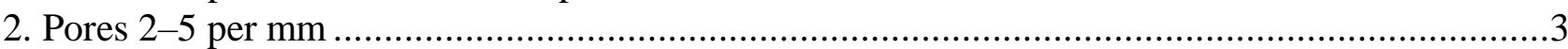

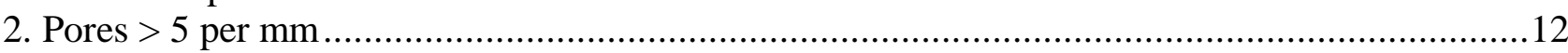


3. Basidiocarps perennial

3. Basidiocarps annual....

4. Cystidioles present, basidiospores broadly ellipsoid, 4.2-5 × 3.1-4 $\mu \mathrm{m}$. Type locality probably France ..F. contigua (Pers.) G. Cunn

4. Cystidioles absent, basidiospores subglobose, 5.1-5.5 × 4-4.5 $\mu \mathrm{m}$. Type locality Mexico.

F. xerophila Raymundo et al.

5. Margin paler than pore surface

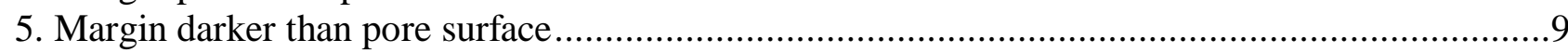

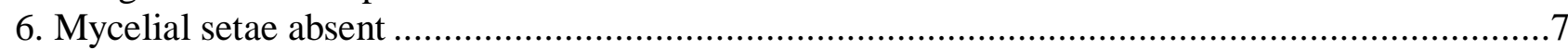

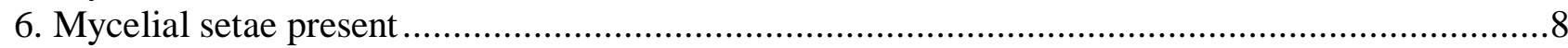

7. Basidiospores $6-8.3 \times 2.4-3 \mu \mathrm{m}$. Type locality China .......................... F. yunnanensis Y.C. Dai

7. Basidiospores 7-8 $\times 1.6-2 \mu \mathrm{m}$. Type locality in Russia..F. contiguiformis (Pilát) Raymundo et al.

8. Basidiospores broadly ellipsoid, $4.2-5 \times 3.1-4 \mu \mathrm{m}, \mathrm{Q}=1.31$. Type locality China F. bambusicola (L.W. Zhou \& B.S. Jia) Q. Chen et al.

8. Basidiospores cylindric, $6-7 \times 2-3 \mu \mathrm{m}, \mathrm{Q}=2.33-2.57$. Type locality USA

9. Mycelial setae swollen and bent near the base. Type locality USA

F. septiseta Y.C. Dai et al. F. americana Y.C. Dai et al.

9. Mycelial setae straight

10. Mycelial setae septate. Type locality China

F. monticola Y.C. Dai et al.

10. Mycelial setae aseptate.

11. Basidiospores cylindric, 5.8-7 × 2.4-3 $\mu \mathrm{m}, \mathrm{Q}=2.32-2.38$. Type locality China.

F. sinica Y.C. Dai et al.

11. Basidiospores broadly ellipsoid, $4-5 \times 2.8-3.5 \mu \mathrm{m}, \mathrm{Q}=1.47-1.57$. Type locality Mexico

F. latispora Y.C. Dai et al.

12. Pores $5-7$ per $\mathrm{mm}$ .13

12. Pores $>7$ per mm. .23

13. Basidiocarps annual 14

13. Basidiocarps perennial .17

14. Basidiospores cylindric .15

14. Basidiospores ellipsoid to broadly ellipsoid .16

15. Cystidioles absent, basidiospores 4.8-6 × 2.8-3.2 $\mu \mathrm{m}, \mathrm{Q}=1.82-1.87$. Type locality Costa Rica. F. centroamericana Y.C. Dai et al.

15. Cystidioles present, basidiospores $5.8-7 \times 2-2.5 \mu \mathrm{m}, \mathrm{Q}=2.57-2.88$. Type locality China F. ramulicola Y.C. Dai \& Q. Chen

16. Basidiospores broadly ellipsoid to drop-shaped, $3-4 \times 2-2.5 \mu \mathrm{m}, \mathrm{Q}=1.37$. Type locality Colombia F. chrysea (Lév.) Baltazar \& Gibertoni

16. Basidiospores ellipsoid, $4.3-5.3 \times 2.8-3.6 \mu \mathrm{m}, \mathrm{Q}=1.47-1.54$. Type locality Thailand

17. Hymenial setae absent. Type locality Cuba F. bambusae Q. Chen et al. F. longisetulosa (Bondartseva \& S. Herrera) Bondartseva \& S. Herrera

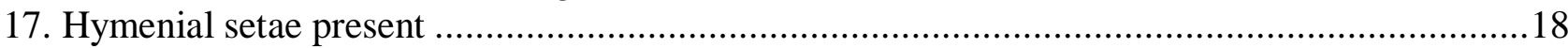

18. Cystidioles present and basidiospores cylindric to subcylindrical ........................................19

18. Cystidioles absent and basidiospores ellipsoid to oblong-ellipsoid 21

19. Skeletal hyphae septate. Type locality Russia.... F. insolita Spirin et al.

19. Skeletal hyphae aseptate.

20. Basidiospores cylindric, 6-7.8 × 2-2.5 $\mu \mathrm{m}, \mathrm{Q}=2.84-3.38$. Type locality France. F. ferrea (Pers.) G. Cunn

20. Basidiospores cylindric to subcylindrical, 4.2-5.2 $\times 2.8-3.5 \mu \mathrm{m}$. Type locality USA. F. punctatiformis (Murrill) Zmitr. et al.

21. Basidiospores oblong-ellipsoid. Type locality Costa Rica................ costaricana Y.C. Dai et al. 21. Basidiospores ellipsoid. 
22. Cystidioles absent; basidiospores 4.5-5.6× 3-3.8 $\mu \mathrm{m}, \mathrm{Q}=1.50-1.65$. Type locality China. .F. karsteniana Q. Chen et al.

22. Cystidioles present; basidiospores 4.1-5.2 $\times 2.8-3.2 \mu \mathrm{m}, \mathrm{Q}=1.55-1.61$. Type locality Germany F. ferruginosa (Schrad.) Murrill

23. Mycelial setae absent ......

23. Mycelial setae present

24. Basidiospores cylindric, 4.2-6.2 × 2-2.6 $\mu \mathrm{m}$. Type locality China.

F. subferrea Q. Chen \& Y. Yuan

24. Basidiospores globose, 4-4.5 × 3-4 $\mu \mathrm{m}$. Type locality Cuba.

F. altocedronensis (Murrill) Bondartseva \& S. Herrera

25. Basidiospores globose and cystidioles present. Type locality Nicaragua.

F. nicaraguensis Murrill

25. Basidiospores ellipsoid and cystidioles absent 26

26. Cystidioles absent.Type locality China. F. subchrysea Q. Chen et al.

26. Cystidioles present. Type locality Cuba......F. rufitincta (Berk. \& M.A. Curtis ex Cooke) Murrill

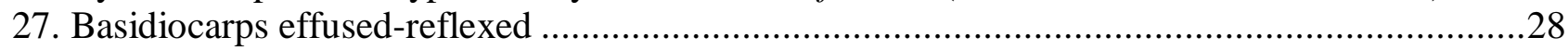

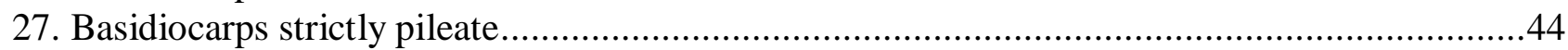

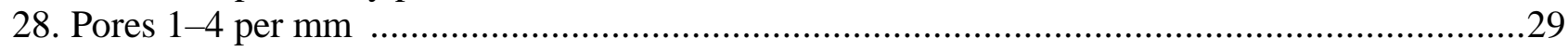

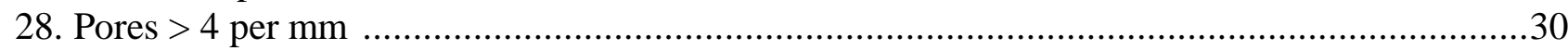

29. Basidiospores 5.5-7 × 1.8-2.5 $\mu \mathrm{m}, \mathrm{Q}=2.92$. Type locality Japan.

F. setifera (T. Hatt.) Y.C. Dai

29. Basidiospores $8-10 \times 2.7-3.5 \mu \mathrm{m}, \mathrm{Q}=2.43$. Type locality USA

30. Basidiocarps perennial

F. palomari Vlasák \& Ryvarden

30. Basidiocarps annual

31. Hymenial setae bifurcate or spiny. Type locality Brazil

31. Hymenial setae simple

F. bifurcata Baltazar et al.

32. Hymenial setae mostly hooked. Type locality Brazil .32

32. Hymenial setae straight F. atlantica Motato-Vásq. et al.

33. Basidiospres cylindric, 7.5-9 $\mu \mathrm{m}$ long. Type locality China

F. acutimarginata Y.C. Dai \& Q. Chen

33. Basidiospres ellipsoid, 3-4 $\mu \mathrm{m}$ long

34. Dissepiments lacerate; cystidioles present. Type locality China.

34. Dissepiments entire; cystidioles absent

F. chinensis Q. Chen et al.

35. Pores $7-10$ per $\mathrm{mm}$

35. Pores 6 per $\mathrm{mm}$

36. Darker line present between the stratified tubes

36. Darker line absent between the stratified tubes ....

37. Basidiocarps subungulate, with finely tomentose anc
F. rhabarbarina (Berk.) Groposo et al.

F. chrysea (Lév.) Baltazar \& Gibertoni

3-3.8 $\mu \mathrm{m}, \mathrm{Q}=1.26-1.39$. Type locality France ........ F. torulosa (Pers.) T. Wagner \& M. Fisch.

37. Basidiocarps applanate, with fuscous to black and lacking finely tomentose or hispid pilear surface, basidiospores 3.8-4.8 × 2.6-3.2 $\mu \mathrm{m}, \mathrm{Q}=1.40-1.60$. Type locality Chile F. senex (Nees \& Mont.) Ghob.-Nejh.

38. Hymenial setae hooked

38. Hymenial setae straight

39. Basidiospores $4-5.2 \times 3.2-4.2 \mu \mathrm{m}, \mathrm{Q}=1.25-1.36$. Type locality South Africa

.F. wahlbergii (Fr.) T. Wagner \& M. Fisch.

39. Basidiospores 4.3-5.5 × 4-4.5 $\mu \mathrm{m}, \mathrm{Q}=1.16-1.22$. Type locality Australia. 
41. Cystidioles present, basidiospores ellipsoid, $4-5 \times 3-3.5 \mu \mathrm{m}, \mathrm{Q}=1.42-1.50$. Type locality USA F. gilva (Schwein.) T. Wagner \& M. Fisch.

41. Cystidioles absent

42. Skeletal hyphae aseptate. Type locality Cuba ..... F. roseocinerea (Murrill) Q. Chen et al.

42. Skeletal hyphae septate

43. Basidiospores ellipsoid, 3.2-4.3 × 2.5-3.2 $\mu \mathrm{m}$. Type locality Cuba

F. flavomarginata (Murrill) Groposo et al.

43. Basidiospores subglobose, ovoid to broadly elipsoid, 4-4.8 $\times 3.2-4 \mu \mathrm{m}$. Type locality Mexico F. mesophila Raymundo et al.

44. Pores $2-5$ per mm. Type locality China.

F. formosana (T.T. Chang \& W.N. Chou) T. Wagner \& M. Fisch.

44. Pores $>5$ per $\mathrm{mm}$.

45. Basidiocarps perennial

45. Basidiocarps annual....

46. Hymenial setae present, hooked, basidiospores broadly ellipsoid to subglobose, $4-5 \times 3.2-4 \mu \mathrm{m}$, $\mathrm{Q}=1.12-1.15$. Type locality China.

F. australasica $\mathrm{Q}$. Chen et al.

46. Hymenial setae absent, basidiospores cylindric, 4.5-5.5 $\times 2-3 \mu \mathrm{m}, \mathrm{Q}=1.63$. Type locality Sri Lanka. F. discipes (Berk.) Y.C. Dai \& Ghob.-Nejh.

47. Hymenial setae absent. Type locality Singapore. F. shoreae Q. Chen et al.

47. Hymenial setae present .48

48. Skeletal hyphae aseptate. Type locality Australia . F. australiana $\mathrm{Q}$. Chen et al.

48. Skeletal hyphae septate

49. Pilear surface nodulose, basidiospores ellipsoid, 3-3.8 $\times 2.2-2.8 \mu \mathrm{m}, \mathrm{Q}=1.31-1.40$. Type locality Australia.... F. plumeriae Q. Chen et al.

49. Pilear surface glabrous, basidiospores oblong ellipsoid to almost sub-cylindrical, $3.5-4.5 \times 2-3$ $\mu \mathrm{m}, \mathrm{Q}=1.43-1.53$. Type locality Madagascar F. callimorpha (Lév.) Groposo et al.

\section{Discussion}

In this study 315 sequences of ITS, nLSU, RPB2 and TEF1 were analyzed, of them 181 sequences, viz. 46 ITS, 49 nLSU, 34 RPB2 and 52 TEF1 are newly generated. Phylogenetic analyses from 105 specimens including 41 species of Fuscoporia were studied; 226 specimens were morphologically examined. Based on laboratory examinations and phylogenetic analyses, nine new species are described and two new combinations are proposed. To date, 49 Fuscoporia species are accepted, but eight species, Fuscoporia altocedronensis (Murrill) Bondartseva \& S. Herrera, F. bifurcata Baltaza et al., $F$. contiguiformis (Pilát) Raymundo et al., $F$. flavomarginata (Murrill) Groposso et al., F. longisetulosa, F. mesophila Raymundo et al., F. nicaraguensis Murrill and $F$. xerophila Raymundo et al., were studied only by literature due to lack of voucher specimens and DNA sequences data. So, their phylogenetic relationships with other species remain uncertain. Our newly described species can be distinghuished from these eight species in morphology. An identification key to 49 accepted species in the genus is provided.

Previously Fuscoporia was defined by a dimitic hyphal system, generative hyphae encrusted with crystals in the dissepiment edge and tube trama, the hymenial setae mostly originating from tramal hyphae and hyaline, thin-walled, smooth basidiospores (Fiasson \& Niemelä 1984, Dai 2010, Chen et al. 2019). However, there are some exceptions like $F$. shoreae, F. longisetulosa and $F$. discipes without hymenial setae. Hence, we re-define the genus as basidiocarps annual to perennial, resupinate to pileate, hyphal system dimitic, generative hyphae encrusted (at least at dissepiments) in most species, hymenial setae usually present, mycelial setae present in some species, and basidiospores hyaline, thin-walled, smooth.

Six groups, Fuscoporia contigua group, $F$. ferrea group, $F$. ferruginosa group, $F$. gilva group, $F$. torulosa group, and $F$. viticola group are recognized with strong support in our phylogenies (Figs 1-2). The Fuscoporia ferrea group includes $F$. ferrea, $F$. punctatiformis (Murrill) Zmitr. et al., $F$. ramulicola, $F$. subferrea and $F$. yunnanensis. These species are characterized by resupinate 
basidiocarps, aseptate skeletal hyphae, absence of mycelial setae, presence of hymenial setae and cystidioles, and cylindric basidiospores (Dai 2010, Chen \& Dai 2019).

The Fuscoporia contigua group includes $F$. americana, $F$. bambusicola, $F$. centroamericana Y.C. Dai, Q. Chen \& J. Vlasák, F. contigua, F. costaricana Y.C. Dai, Q. Chen \& J. Vlasák, F. latispora, F. monticola, F. rufitincta (Berk. \& M.A. Curtis ex A.L. Sm.) Murrill, F. septiseta and F. sinica. Species in this group are characterized by resupinate basidiocarps, moderately large pores, presence of long mycelial setae and large hymenial setae (Niemelä 2005, Ryvarden \& Melo 2017, Chen et al. 2019).

The Fuscoporia ferruginosa group includes $F$. ferruginosa, $F$. karsteniana, F. bambusae and $F$. subchrysea. These species are characterized by resupinate basidiocarps, relatively small pores, entire dissepiments, straight hymenial setae, presence of mycelial setae and ellipsoid basidiospores. In our phylogeny (Fig. 2), samples of $F$. ferruginosa nested in two independent lineages, one lineage represented by American and Chinese samples, another by European samples. Because the type locality of $F$. ferruginosa is Germany, it means that the European samples represent the real $F$. ferruginosa, and the American and Chinese samples may be new species. The European specimens can be segregated from American and Chinese ones by perennial basidiocarps (annual in the latter) and smaller pores (6-8 per $\mathrm{mm}$ in the former and 5-6 per $\mathrm{mm}$ in the latter). Because some synonyms of $F$. ferruginosa were described from North America, for the time being we treat all these samples as $F$. ferruginosa.

The Fuscoporia gilva group including $F$. atlantica, $F$. australiana, $F$. chinensis, $F$. formosana, $F$. gilva, $F$. plumeriae, and $F$. setifera. These species are characterized by effused-reflexed to pileate basidiocarps, indistinctly concentrically sulcate with zones, hispid to rugose or nodulose pileal surface, lacerate dissepiments, presence of cystidioles and ellipsoid to cylindric basidiospores. Fuscoporia gilva was originally described as Boletus gilvus Schwein. from USA (Schweinitz 1822), and it is a common fungus on hardwoods in southwest America (Gilbertson 1979). Abundant specimens of $F$. gilva sensu lato were collected from China, but most of them are in fact $F$. chinensis, which differ from $F$. gilva by the aseptate skeletal hyphae and smaller basidiospores (3-4 $\times 2-2.5 \mu \mathrm{m}$ vs. $4-5 \times 3-3.5 \mu \mathrm{m}$, Gilbertson 1979). Several synonyms of $F$. gilva were described from Argentina, France, North America and New Zealand. We have studied these taxa following the literature (Polyporus balansae Speg., Spegazzini 1884, Placodes fucatus Quél., Quélet 1887, Polyporus calvescens Berk., Berkeley 1839, Polyporus gilvorigidus Lloyd, Lloyd 1925) and our newly described species $F$. chinensis is different from these taxa.

The Fuscoporia torulosa group includes F. callimorpha, F. torulosa (Pers.) T. Wagner \& M. Fisch., F. rhabarbarina (Berk.) Groposo et al. and F. senex (Nees \& Mont.) Ghob.-Nejh., $F$. wahlbergii, F. australasica, F. eucalypti, F. roseocinerea, F. chrysea and $F$. shoreae. Species in this group are characterized by the resupinate, effused-reflexed to pileate basidiocarps, small pores (5-10 per $\mathrm{mm}$ ), entire dissepiments, septate skeletal hyphae, straight or hooked hymenial setae, lacking mycelial setae, presence of cystidioles, broadly ellipsoid to subglobose basidiospores. Fuscoporia senex is very close to $F$. rhabarbarina in phylogeny (Fig. 2), but $F$. rhabarbarina has a distinctive black crust at upper surface, smaller basidiospores and skeletal hyphae swelling in $\mathrm{KOH}$ (Singer 1959, Bakshi et al. 1970, Ryvarden \& Johansen 1980, Corner 1991, Groposo et al. 2007). Specimens from type locality of these two species should be compared and phylogenetically analyzed in the future. Fuscoporia callimorpha present a pantropical distribution (Ryvarden \& Johansen 1980, Lowe 1957, Loguercio-Leite \& Wright 1995, Groposo et al. 2007, Raymundo et al. 2013a), and it is easily separated from other species in the group by smaller basidiospores (3.5-4.5 $\times 2.4-3 \mu \mathrm{m}$, Ryvarden \& Johansen 1980). Fuscoporia wahlbergii was reported to have a wide distribution among pantropical zones (Ryvarden \& Johansen 1980, Ryvarden \& Gilbertson 1994, Loguercio-Leite \& Wright 1995, Wagner \& Fischer 2001), despite the species was originally described from South Africa. No sequences of $F$. wahlbergii from the type locality are avialble and we presume that the species has a wide distribution in Europe, USA, Australia and Asia, so specimens from these areas are treated as $F$. wahlbergii in our study. The Chinese samples previously treated as $F$. wahlbergii in Dai (2010) are in fact different from the type description of $F$. 
wahlbergii, because the spores from the type of $F$. wahlbergii are globose, 3.5-4 $\mu \mathrm{m}$ in diam. (Reid 1975), and now Chinese specimens were described as F. australasica. Fuscoporia atlantica from Brazil also has hooked hymenial setae and ellipsoid basidiospores, but the species clustered into $F$. gilva group (Pires et al. 2015).

The Fuscoporia viticola group includes $F$. palomari Vlasák \& Ryvarden and F. viticola (Schwein.) Murrill. The two species are characterized by resupinate to effused-reflexed basidiocarps, moderately large pores $(<7$ per $\mathrm{mm})$, absence of mycelial setae, narrowly subulate and long hymenial setae (> $40 \mu \mathrm{m}$ long), cylindric and long basidiospores (> $7 \mu \mathrm{m}$ long). This small group is distinguished from other groups by the longer hymenial setae and larger basidiospores (Vlasák et al. 2012).

Fuscoporia acutimarginata, F. discipes, F. insolita Spirin, Vlasák \& Niemelä are nested in three subclades (Fig. 2), but without enough support. They certainly do not belong to a group, and are different from the above mentioned six groups. For the time being we do not treat them in any groups.

\section{Acknowledgements}

The authors would like to express their deep thanks to Prof. Bao-Kai Cui (Beijing Forestry University, China) for forwarding his specimens to us for the study. This study was financed by the National Natural Science Foundation of China (Project Nos. 31530002, 31900019).

\section{References}

Anonymous. 1969 - Flora of British fungi. Colour identification chart. London: Her Majesty's Stationery Office.

Bakshi BK, Sen M, Singh B. 1970 - Cultural diagnosis of Indian Polyporaceae. 2. Genera Fomes and Trametes. Indian Forest Records 2, 245-276.

Baltazar JM, Gibertoni TB. 2010 - New combinations in Phellinus s.l. and Inonotus s.l. Mycotaxon 111, 205-208.

Baltazar JM, Trierveiler-Pereira L, Loguercio-Leite C, Ryvarden L. 2009 - Santa Catarina Island mangroves 3: a new species of Fuscoporia. Mycologia 100, 859-863.

Berkeley MJ. 1839 - Descriptions of exotic fungi in the collection of Sir W.J. Hooker, from memoirs and notes of J.F. Klotzsch, with additions and corrections. Annals and Magazine of Natural History 3, 375-401.

Chang TT, Chou WN. 1998 - Two new species of Inonotus from Taiwan. Mycological Research 102, 788-790.

Chen JJ, Cui BK, Dai YC. 2016 - Global diversity and molecular systematics of Wrightoporia s. 1. (Russulales, Basidiomycota). Persoonia 37, 21-36.

Chen Q, Dai YC. 2019 - Two new species of Fuscoporia (Hymenochaetales, Basidiomycota) from southern China based on morphological characters and molecular evidence. Mycokeys 61, $75-89$.

Chen Q, Wu F, Ji XH, Si J et al. 2019 - Phylogeny of the genus Fuscoporia and taxonomic assessment of the $F$. contigua group. Mycologia 111, 1-22.

Chen Q, Yuan Y. 2017 - A new species of Fuscoporia (Hymenochaetales, Basidiomycota) from southern China. Mycosphere 8, 1238-1245.

Corner EJH. 1991 - Ad Polyporaceas 7. The xanthochroic polypores. Nova Hedwigia 101, 1-175.

Cunningham GH. 1948 - New Zealand Polyporaceae 2. The genus Fuscoporia. Bulletin of the New Zealand Department of Industrial Research 73, 1-14.

Dai YC. 1999 - Phellinus sensu lato (Aphyllophorales, Hymenochaetaceae) in East Asia. Acta Botanica Fennica 166, 1-115.

Dai YC. 2000 - A checklist of polypores from Northeast China. Karstenia 40, 23-29.

Dai YC. 2010 - Hymenochaetaceae (Basidiomycota) in China. Fungal Diversity 45, 131-343. 
Dai YC, Cui BK, Yuan HS, Li BD. 2007 - Pathogenic wood-decaying fungi in China. Forest Pathology 37, 105-120.

Dai YC, Zhou LW, Cui BK, Chen YQ, Decock C. 2010 - Current advances in Phellinus sensu lato: medicinal species, functions, metabolites and mechanisms. Applied Microbiology and Biotechnology 87, 1587-1593.

Felsenstein J. 1985 - Confidence intervals on phylogenetics: an approach using bootstrap. Evolution 39, 783-791.

Fiasson JL, Niemelä T. 1984 - The Hymenochaetales: a revision of the European poroid taxa. Karstenia 24, 14-28.

Gilbertson RL. 1979 - The genus Phellinus (Aphyllophorales: Hymenochaetaceae) in western North America. Mycotaxon 9, 51-89.

Groposo C, Loguercio-Leite C, Góes-Neto A. 2007 - Fuscoporia (Basidiomycota, Hymenochaetales) in southern Brazil. Mycotaxon 101, 55-63.

Hall TA. 1999 - Bioedit: a user-friendly biological sequence alignment editor and analysis program for Windows 95/98/NT. Nucleic Acids Symp Ser 41, 95-98.

Index Fungorum. 2020 - http://www.indexfungorum.org/names/Names.asp (accessed: March 2020). Jeewon R, Hyde KD. 2016 - Establishing species boundaries and new taxa among fungi: recommendations to resolve taxonomic ambiguities. Mycosphere 7, 1669-1677.

Larsen MJ, Cobb-Poulle LA. 1990 - Phellinus (Hymenochaetaceae). A survey of the world taxa. Synopsis Fungorum 3, 1-206.

Larsson KH, Parmasto E, Fischer M, Langer E et al. 2006 - Hymenochaetales: a molecular phylogeny for the hymenochaetoid clade. Mycologia 98, 926-936.

Lloyd CG. 1925 - Mycological Notes 74. Mycological Writings 7, 1333-1348.

Loguercio-Leite C, Wright JE. 1995 - The genus Phellinus (Hymenochaetaceae) on the Island of Santa Catarina, Brazil. Mycotaxon 54, 361-388.

Lowe JL. 1966 - Polyporaceae of North America. The genus Poria. State University College of Forestry at Syracuse University Technology Publication 90, 1-183.

Lowe JL. 1957 - Polyporaceae of North America. The genus Fomes. State University College of Forestry at Syracuse University, Technical publication 80, 1-97.

Nylander J. 2004 - MrModeltest v2. Program distributed by the author. Uppsala: Evolutionary Biology Centre, Uppsala University.

Matheny PB. 2005 - Improving phylogenetic inference of mushrooms with RPB1 and RPB2 nucleotide sequences (Inocybe, Agaricales). Mollecular Phylogenetics and Evolution 35, 120.

Murrill WA. 1907 - Polyporaceae, Part 1. North American Flora 9, 1-72.

Murrill WA. 1908 - Polyporaceae, Part 2. North American Flora 9, 73-131.

MycoBank. 2020 - www.mycobank.org/Biolomics.aspx ?Table=Mycobank\&Page=200\&ViewMod e=Basic (accessed: March 2020).

Niemelä T. 2005 - Polypores, lignicolous fungi. Norrlinia 13, 1-320.

Niemelä T, Wagner T, Fischer M, Dai YC. 2001 - Phellopilus gen. nov. and its affinities within Phellinus s. lato and Inonotus s. lato (Basidiomycetes). Annales Botanici Fennici 38, 51-62.

Overholts LD. 1953 - The Polyporaceae of the United States, Alaska and Canada. University Michigan Press, Ann Arbor.

Petersen JH. 1996 - Farvekort. The Danish Mycological Society's colour-chart. Greve: Foreningen til Svampekundskabens Fremme, Greve 1-6.

Pires RM, Motato-Vásquez V, Gugliotta AM. 2015 - Fuscoporia atlantica sp. nov., a new polypore from the Brazilian Atlantic Rainforest. Mycotaxon 130, 843-855.

Posada D, Crandall KA. 1998 - Modeltest: testing the model of DNA substitution. Bioinformatics $14,817-818$.

Quélet L. 1887 - Quelques especes critiques ou nouvelles de la Flore Mycologique de France. Comptes Rendus de l'Association Française pour l'Avancement des Sciences 15, 484-490. 
Raymundo T, Valenzuela R, Bautista-Hernández S, Esqueda M et al. 2013a - The genus Fuscoporia (Hymenochaetales, Basidiomycota) in Mexico. Revista Mexicana de Biodiversidad 84, 50-69.

Raymundo T, Valenzuela R, Esqueda M. 2013b - Hymenochaetaceae from Mexico 6. A new Fuscoporia species from the Sonoran Desert. Mycotaxon 125, 37-43.

Rehner SA, Buckley E. 2005 - A Beauveria phylogeny inferred from nuclear ITS and EF1-a sequences: evidence for cryptic diversification and links to Cordyceps teleomorphs. Mycologia 97, 84-98.

Reid DA. 1975 - Type studies of the larger Basidiomycetes described from South Africa. Contributions from the Bolus Herbarium 7, 1-255.

Reid DA. 1976 - Notes on polypores. 2. Memoirs of the New York Botanical Garden 28, 179-198.

Ryvarden L. 2004 - Neotropical polypores 1. Introduction, Hymenochaetaceae and Ganodermataceae. Synopsis Fungorum 19, 1-227.

Ryvarden L. 2005 - The genus Inonotus, a synopsis. Synopsis Fungorum 21, 1-149.

Ryvarden L, Gilbertson RL. 1994 - European polypores 2. Synopsis Fungorum 7, 394-743.

Ryvarden L, Johansen I. 1980 - A preliminary polypore flora of East Africa. Fungiflora, Norway 1636.

Ryvarden L, Melo I. 2017 - Poroid fungi of Europe, 2nd edition. Synopsis Fungorum 37, 1-431.

Schweinitz LD. 1822 - Synopsis fungorum Carolinae superioris. Schriften der Naturforschenden Gesellschaft zu Leipzig 1, 21-31.

Silvestro D, Michalak I. 2012 - RaxmlGUI: a graphical front-end for RAxML. Organisms Diversity and Evolution 12, 335-337.

Singer R. 1959 - Basidiomycetes from Masatierra (Juan Fernandez Islands, Chile). Ark Bot 4, 370400.

Spegazzini C. 1884 - Fungi Guaranitici. Pugillus 1. Anales de la Sociedad Científica Argentina 17, $42-48$.

Spirin V, Vlasák J, Niemelä T. 2014 - Fuscoporia insolita (Hymenochaetales, Basidiomycota), a new species from Russian Far East. Annales Botanici Fennici 51, 403-406.

Stamatakis A. 2006 - RAxML-VI-HPC: maximum likelihood-based phylogenetic analyses with thousands of taxa and mixed models. Bioinformatics 22, 2688-2690.

Swofford DL. 2002 - PAUP*: Phylogenetic analysis using parsimony (*and other methods). Version 4.0b10. Massachusetts: Sinauer Associates.

Song J, Cui BK. 2017 - Phylogeny, divergence time and historical biogeography of Laetiporus (Basidiomycota, Polyporales). BMC Evolutionary Biology 17, 102.

Thompson JD, Gibson TJ, Plewniak F, Jeanmougin F, Higgins DG. 1997 - The clustal_X windows interface: Flexible strategies for multiple sequence alignment aided by quality analysis tools. Nucleic Acids Research 25, 4876-4882.

Vilgalys R, Hester M. 1990 - Rapid genetic identification and map- ping of enzymatically amplified ribosomal DNA from several Cryptococcus species. Journal of Bacteriology 172, 4238-4246.

Vlasák J, Vlasák J Jr, Ryvarden L. 2012 - Four new polypore species from the western United States. Mycotaxon 119, 217-231.

Wagner T, Fischer M. 2001 - Natural groups and a revised system for the European poroid Hymenochaetales (Basidiomycota) supported by nLSU rDNA sequence data. Mycological Research 105, 773-782.

Wagner T, Fischer M. 2002 - Proceedings towards a natural classification of the worldwide taxa Phellinus s.l. and Inonotus s.l., and phylogenetic relationships of allied genera. Mycologia 94, 998-1016.

White TJ, Bruns TD, Lee S, Taylor J. 1990 - Amplification and direct sequencing of fungal ribosomal RNA genes for phylogenetics. In: Innis MA, Gelfand DH, Sninsky JJ, White TJ, eds. PCR protocols: A guide to methods and applications. New York: Academic Press 315322. 
Wu F, Zhou LW, Yang ZL, Bau T et al. 2019 - Resource diversity of Chinese macrofungi: edible, medicinal and poisonous species. Fungal Diversity 98, 1-76.

Zhou LW, Jia BS. 2010 - A new species of Phellinus (Hymenochaetaceae) growing on bamboo in tropical China. Mycotaxon 114, 211-216.

Zhou LW, Vlasák J, Dai YC. 2016 - Taxonomy and phylogeny of Phellinidium (Hymenochaetales, Basidiomycota): a redefinition and the segregation of Coniferiporia gen. nov. for forest pathogens. Fungal Biology 120, 988-1001.

Zhu L, Song J, Zhou JL, Si J, Cui BK. 2019 - Species diversity, phylogeny, divergence time and biogeography of the genus Sanghuangporus (Basidiomycota). Frontiers in Microbiology 10, 812.

Zmitrovich IV, Malysheva VF. 2014 - Studies on Oxyporus I. Segregation of Emmia and general topology of phylogenetic tree. Mycology and Phytopathology 48, 161-171. 